\title{
6 Poetischer Synchronismus in Ovids „Metamorphosen“
}

Wie bereits festgestellt, kann Synchronismus zweierlei bedeuten: zum einen eine Anordnungs- bzw. Überleitungstechnik, zum anderen einen poetischen Synchronismus, der als eine Form zeitlicher Inkonsistenz näher zu betrachten sein wird.

\subsection{Exkurs: Synchronismus vs. poetischer Synchronismus}

Zuvor aber einige wenige Bemerkungen zu ersterem Fall: Ovid begegnet dem in den „Metamorphosen“ wegen der vielen verschiedenen Einzelsagen zwangsläufigen Erfordernis, nach Abschluss der einen Geschichte einen Übergang zur nachfolgenden herstellen zu müssen, ${ }^{1}$ nicht selten damit, dass beide Handlungsstränge mittels einer vorhandenen oder behaupteten Synchronizität zueinander in Beziehung gesetzt sind. Als beispielsweise die Flussgottheiten Mittel- und Südgriechenlands zusammenkommen, um ihrem Genossen Peneios Trost zu spenden - seine Tochter Daphne ist gerade in einen Baum verwandelt worden -, fehlt Inachos als einziger, da er just zum gleichen Zeitpunkt von der Trauer um das Verschwinden seiner eigenen Tochter Io eingenommen ist. ${ }^{2}$ Was dann folgt, ist die Darlegung der Umstände, die zu der Abwesenheit Ios und dem Kummer ihres Vaters geführt haben. ${ }^{3}$ Gleichzeitigkeit bildet die logische Verknüpfung zwischen den einzelnen Episoden, die in diesem Fall durch die thematische Parallele zusätzlich bestärkt wird. ${ }^{4}$ Damit ist aber zunächst nicht impliziert, dass Objekte zu einer Zeit Eigenschaften haben, zu der sie ihnen nicht zukommen dürfen, definitionsgemäß das Prinzip der Aktualisierungen. ${ }^{5}$

Ausgeschlossen ist dadurch jedoch nicht, dass ein poetischer Synchronismus gewissermaßen als Additum auch bei einer synchronistischen Überleitung vorliegt. ${ }^{6}$ Weil es aber dem eigentlichen Zweck dieser Übergänge, zwei an sich nicht zusammengehörige Erzählstränge mit einer gewissen Plausibilität aneinanderzuknüpfen,

\footnotetext{
1 Quintilian führt diese Notwendigkeit (necessitas) sogar als entlastenden Grund für mitunter allzu pointierte Überleitungen in den „Metamorphosen“ an, weil Ovid ja ,sehr verschiedene Gegenstände in der Gestalt eines einzigen Ganzen vereinend“ (res diversissimas in speciem unius corporis colligentem inst. IV, 1, 77.) darstellt.

2 Vgl. met. I, 577-585. Die geographische Besonderheit, dass ein Fluss aus der Argolis zum Peneios nach Thessalien hätte kommen können, ist nebenbei bemerkt hier sogar lösbar, weil ein verschwundener Nebenarm des Acheloos in Thessalien ebenso Inachos hieß und man in der Antike eine unterirdische Verbindung vermutete. Vgl. Bömer 1969, ad met. I, 583.

3 Für eine detailliertere Besprechung der Stelle unter diesen Aspekten s. Wheeler 2000, 58 -63.

$4 \mathrm{Zu}$ weiteren Beispielen s. Wheeler 2002, 186f.; Cole 2004, 372f. und Cameron 2004, $285 \mathrm{f}$.

5 S. o. Kap. 3.3.1.

6 Hierzu müsste schließlich nur eine Synchronizität als verbindendes Glied genutzt sein, die sich gegenüber anderen nicht-diegetischen Zeugnissen als widersprüchlich erweist.
} 
entgegenstünde, sind poetische Synchronismen hierfür primär nicht relevant. Denn eine solche Synchronizität, die sich als allzu sehr bemüht oder als widersprüchlich erweist, würde die Glaubwürdigkeit der behaupteten Geschehensabfolge eher infrage stellen, als dass sie sie etablieren hilft. $^{7}$

Unscheinbarer und wohl hauptsächlich von Interesse für quellenkritische, die mythologische Überlieferung systematisch untersuchende Fragestellungen sind all die Synchronismen in den „Metamorphosen“, die als Anordnungsprinzip Mythenstränge teilweise länder- und kulturübergreifend miteinander verbinden: ${ }^{8}$ z.B. im vierten Buch, in dem Leukothoe, die intradiegetisch ergänzte Affäre des Sonnengottes Sol, derselben Generation zugewiesen wird wie Klymene, die Mutter Phaethons, dessen Zweifel, dass Sol sein Vater sei, und seine katastrophalen Konsequenzen im ersten und zweiten Buch geschildert sind. ${ }^{9}$ Der Unterschied zu den poetischen Synchronismen ist auch hier das zugrunde liegende Bestreben, der Polyphonie des Mythos eine darstellungskonforme Ordnung abzugewinnen, dem aber die zeitliche Widersprüchlichkeit, wie sie für jenes Phänomen konstitutiv ist, zuwiderläuft.

An diesem die Zeit der Erzählung stabilisierenden und strukturierenden Aspekt ist überdies aus seinem Gegenteil erkennbar, dass etwaige destabilisierende Verfahren dann zum einen nur dort in Erscheinung treten können, wo eine narrative oder diegetisch-historische Strukturierung so deutlich vorhanden ist, dass eine Abweichung davon als signifikant wahrgenommen werden kann; ${ }^{10}$ und dass diese zum anderen ein nicht unwesentlicher Widerspruch zu einer Ordnung sind, die die Erzählung generell eigentlich herzustellen bemüht ist.

\subsection{Attribuierte Gleichzeitigkeit - met. VI, 412-423}

Die erste vorzustellende Passage ist insofern eine doppelte Vorwegnahme, als sie einerseits nicht die chronologisch früheste Fundstelle im Gedicht ist und andererseits die Beachtung von Aktualisierungen und Anachronismen miteinschließt. Als weiteres Beispiel für die Verwobenheit und gegenseitige Bedingtheit der zeitlichen Referenzen dieses Textes mag dies aber dennoch sehr passend sein. ${ }^{11}$

7 S.u. das nächste Kapitel für weitere Beobachtungen dazu.

8 Dass Ovid solche Synchronismen aber auch bewusst unterlässt, sollte mit Feeney 1999, 22, nicht vergessen werden.

9 Vgl. Cole 2004, $360 \mathrm{f}$.

10 Dies führt wieder zurück zu Wheelers fünftem Kapitel „Discourse of Time“, wo auf eben diese Spannung eingegangen wird. Vgl. bes. Wheeler 1999a, 117-125. Direkt in Bezug auf Synchronismen kommt nun auch Farrell 2020, 333, zu diesem Schluss.

11 Diese Passage steht nach Ansicht vieler außerdem an der Schnittstelle zwischen zwei großen thematischen Einheiten. Vgl. Otis ${ }^{2} 1970$, 84f. und Feeney 1999, 18. Interessant für die weitere Beschäftigung ist auch folgende Einschätzung: „Wenn man meint, die Metamorphosen irgendwo ,historisch“ werden lassen zu müssen, dann kommt überhaupt nur allenfalls met. 6,421 in Frage“ (Schmidt 1991, 124). 


\title{
6.2.1 Eine aktualisierende, anachrone, syn- und anachronistische Überleitung?
}

Die Ausgangssituation ist die: In Theben betrauert Pelops - nach dem Tod von Amphions und Niobes Kindern sowie von Amphion selbst - als einziger seine Schwester Niobe, die als Verursacherin dieser Katastrophe gesehen wird. Hierbei macht er sie auf sein eigenes Schicksal aufmerksam: Sein Vater Tantalus hat ihn zerstückelt und den Göttern zum Mahl vorgesetzt, die ihn dann aber wieder zusammengesetzt und, als Ersatz für die unwissentlich verspeiste, mit einer neuen Schulter aus Elfenbein versehen haben. ${ }^{12}$ Hieran schließt sich unmittelbar folgender Text an:

\author{
Finitimi proceres coeunt, urbesque propinquae \\ oravere suos ire ad solacia reges, \\ Argosque et Sparte Pelopeiadesque Mycenae \\ et nondum torvae Calydon invisa Dianae \\ Orchomenosque ferax et nobilis aere Corinthus \\ Messeneque ferox Patraeque humilesque Cleonae \\ et Nelea Pylos neque adhuc Pittheia Troezen, \\ quaeque urbes aliae bimari clauduntur ab Isthmo \\ exteriusque sitae bimari spectantur ab Isthmo. \\ credere quis posset? solae cessastis Athenae. \\ obstitit officio bellum, subvectaque ponto \\ barbara Mopsopios terrebant agmina muros. ${ }^{13}$
}

Gleich für den Beginn stellt Bömer fest, dass durch die aktualisierende Gegenüberstellung des Landadels (finitimi proceres - 412) und der Städte, in denen Könige öffentlich beauftragt werden (oravere suos reges - 413), die Darstellung weniger „durch einen Blick auf (rekonstruierte) historische Verhältnisse bedingt“ sei als durch das „poetische Prinzip der Variation." ${ }^{14}$ Die Aktualisierung selbst wird durch officio (422) konzeptuell noch einmal aufgegriffen und in ihrer Aussage bestätigt. ${ }^{15}$

12 Vgl. met. VI, 401-411.

13 Met. VI, 412-423: ,Die benachbarten Adligen kommen zusammen, und die Städte aus der Umgebung baten ihre Könige, zum Trostspenden dorthin zu gehen: Argos und Sparta und das pelopeiadische Mykene und Kalydon, noch nicht verhasst der finster blickenden Diana, und das fruchtbare Orchomenos und das erzberühmte Korinth und das wilde Messene und Patrai und das niedrig gelegene Kleonai und das neleische Pylos und Troizen, noch nicht pittheisch, und die anderen Städte, die vom Isthmus, der zwei Meere berührt, eingeschlossen, und die, die vom Isthmus, der zwei Meere berührt, als außerhalb liegend betrachtet werden. Wer hätte das glauben können? Einzig du, Athen, warst säumig. Krieg stand der Pflicht im Wege, und fremdländische Heerscharen, auf dem Meer herangefahren, setzten die Mopsopischen Mauern in Schrecken. 'Vgl. Bömer ${ }^{2} 2008$, ad loc.

14 Ebd., ad met. VI, 412.

15 Deshalb dürfte die Erklärung Bömers, dass Ovid den Gegensatz finitimi-propinqui allein um der Abwechslung willen nutzt, nicht das ganze hier gegebene Sinnpotenzial erschließen - ungeachtet dessen, dass der durch diese Aktualisierung eingerahmte Teil weitere sehr augenscheinliche Indizien liefert, die zeitlichen Relationen für etwas komplexer und bedeutungsvoller zu halten. 
Es hat daher den Anschein, als handelte es sich um eine ganz konventionelle synchronistische Überleitung von Theben nach Athen, die durch die Nennung von Pelops in Vers 411 und Pandion im Anschluss (namentlich angeführt in 426) relativ exakt genealogisch und damit auch zeitlich verortet wird. ${ }^{16}$ Überaus auffällig sind aus diesem Grund die Epitheta ornantia mancher Städte: Mykene wird als Pelopeiades (414) bezeichnet, obwohl es mindestens erst durch Pelops' Sohn Atreus ,pelopeiadisch ${ }^{6}$ wird, ${ }^{17}$ Korinth als nobilis aere (416), obwohl diese Berühmtheit erst in späterer Zeit, womöglich erst seit dem 2. Jahrhundert v. Chr. sprichwörtlich war, ${ }^{18}$ und Messene als ferox (417), obwohl die Stadt erst sehr viel später diesen Namen erhält und auch dieses Attribut erst auf den kriegerischen Konflikt mit Sparta im achten und siebten Jahrhundert v. Chr. zurückzuführen ist. ${ }^{19}$ Als eine durch die Erzählerperspektive legitimierte Vorwegnahme sind diese Attribute typische Aktualisierungen. ${ }^{20}$

Angenommen aber, man hielte dies für beliebige schmückende Beiworte und mäße diesen Adjektiven kein oder nur wenig Gewicht bei, so fordern die beiden mit nondum (415) und neque adhuc (418) gekennzeichneten Epitheta eine differenziertere Auseinandersetzung ein, da sie einer gewissen Rücksicht Ausdruck verleihen, wonach die über diese Attribute ausgedrückten zeitlichen Verhältnisse zu diesem Zeitpunkt nicht zutreffend sind: Kalydon, von dem erst zwei Bücher später erzählt wird, warum es bzw. wer genau diese Reaktion bei Diana verursacht, ${ }^{21}$ und Troizen, das erst eine Generation später unter der Herrschaft des Pittheus, traditionsgemäß auch ein Pelopssohn, stehen wird.

16 Bei Haupt ${ }^{11} 1969,333$, wird als Parallele für den hier vorliegenden Synchronismus nicht zufällig das oben erwähnte Peneios-Beispiel genannt, das auch für Farrell 2020, 333, ein für die „Metamorphosen“Erzählung emblematischer Synchronismus ist. S. dazu dann u. Kap. 6.2.2.

17 Pelopeias ist ein ovidisches Hapaxlegomenon, das neben dieser Stelle nur noch in Ov. fast. III, 89 vorkommt, wo es neben Sparta und Argos wohl das von den Pelopsenkeln beherrschte Mykene meint. OLD (,of or belonging to Pelops or his race`) und Georges (,pelopëisch, peloponnesisch') sind hierzu auffallend vage. Mit Bömer 1958, ad fast. III, 89, wird aber deutlich, dass dieses Adjektiv erst durch Atreus auf Mykene zutreffen kann.

18 Vgl. Anderson 1972, ad loc. Eine frühere, indirekte Aktualisierung bei Korinth liegt außerdem vor in met. V, 407 f. Vgl. Bömer 22011, ad met. V, $407 \mathrm{f}$.

19 Vgl. die treffende Analyse bei Solodow 1988, 81. Die eher unscheinbaren Beiwörter ferax (416) bei Orchomenos und humiles (417) bei Kleonai könnten auch als Aktualisierungen in Erwägung gezogen werden, da sie sicher spätere Zuschreibungen sind; aufgrund ihrer zeitlich indifferenten Bedeutung für die direkte diegetische Umgebung, die bei humiles außerdem nicht eindeutig geklärt ist (vgl. Bömer ${ }^{2} 2008$, ad loc.), sei dies zunächst nur am Rande vermerkt (Weiteres dann unten in Kap. 6.2.2). Inwiefern die Aktualisierung bei Korinth und die von Rosati nur angedeuteten ,altri ,anacronismi““ dazu dienen, einen lebendigen Dialog mit dem Leser und seiner konkreten Erfahrung herzustellen (vgl. Rosati ${ }^{2} 2013$, ad met. VI, 419-420), müsste dann im Lichte der kurz vorher stehenden Aussage, dass der Katalog auf affirmative Weise „uno snodo essenziale per ricostruire la struttura cronologica del poema“ (ebd., ad met. VI, 412-423) sei, eigentlich noch genauer diskutiert werden.

20 Auch Servius diskutiert genau solche Fälle in der „Aeneis“ als anticipatio. Vgl. Bömer ${ }^{2} 2008$, ad met. VI, 417. S. o. Kap. 3.1.2 und S. 60, Anm. 179.

21 Vgl. met. VIII, 273-278. 
Einerseits wird damit das hic et nunc der gegenwärtigen Situation aus dem Kontrast zu dem, was noch nicht eingetreten ist, konsolidiert und letztlich auch der mit dieser kurzen Passage intendierte Übergang vom amphionischen Theben zum pandionischen Athen nachvollziehbar gemacht. ${ }^{22}$ Dadurch aber, dass diese gekennzeichneten Prolepsen bei den anderen Attributen eben nicht stehen, implizieren sie dort andererseits, dass der bei diesen Epitheta zum Ausdruck kommende Zeitaspekt, eben weil er nicht relativiert wird, uneingeschränkt gültig ist: Korinth, so ist man angehalten zu schlussfolgern, ist das erzberühmte und Messene (nicht Ithome, wie es womöglich zutreffender genannt werden müsste) ist das wilde zu jener Zeit, als alle Städte zur Kondolenz eine Gesandtschaft nach Theben schicken. Gemeinsam mit der eingangs aufgezeigten Aktualisierung und mit den aktualisierenden Attributen führt diese Beachtung innerdiegetischer Zeitstrukturen $\mathrm{zu}$ einem Nebeneinander an sich heterogener Zuschreibungen, denen eine letztgültige Homogenität nur schwerlich abzugewinnen ist.

Dies ist noch zusätzlich durch eine mögliche intratextuelle Dimension gesteigert, da die genannte Städte auch gegenseitig zueinander in Beziehung gesetzt werden können: Das vermeintlich neutrale Sparte (414) ist schließlich der Kriegsgegner, durch den Messene den Beinamen ferox erst erhält; und wenn für den Status von Troizen die Bezeichnung Pittheia noch nicht (neque adhuc) gilt, weil dieser Pelopssohn noch nicht herrscht, dann ist bei Mykene immerhin verwunderlich, dass dort jener andere Pelopide die Macht bereits ergriffen zu haben scheint und dass das hierfür verwendete Adjektiv Pelopeias sogar viel enger auf den nur drei Verse vorher erwähnten Pelops zurückweist als im Falle von Troizen. ${ }^{23}$ Der über die Aktualisierung aufgerufene Zu-

22 Für ein Ereignis wie die kalydonische Jagd, die schon bei Homer durch mehrere Aussagen unmissverständlich in die Zeit vor dem trojanischen Krieg lokalisiert wird und deswegen neben anderen einschlägigen Mythen wie z.B. der Argonautenfahrt oder den Taten des Herakles ein wichtiger prätrojanischer Referenzpunkt ist, gilt das in besonderem Maß. Vgl. auch Rosati ${ }^{2} 2013$, ad met. VI, 415. 23 Natürlich könnte man argumentieren, dass Ovid hier genau den Zustand einfangen möchte, in dem Mykene schon, aber Troizen noch nicht pelopeisch ist. Die Polyvalenz der Zeitbezüge aber, ganz ungeachtet der Frage, ob eine solche historische Absicht überhaupt bestanden haben kann, macht diese Exaktheit schon bei oberflächlicher Betrachtung unwahrscheinlich. Die Lesart von Cole 2008, 22, der Pelopeiades (in Cole 2004, 360, fälschlich Pelopeides) positivistisch direkt auf Pelops bezieht und ihn damit zu einem Gesandten aus der Stadt Mykene macht, obwohl er ja eigentlich schon bei seiner Schwester ist und als einziger mit ihr trauert (das geht hervor aus met. VI, 403-406, auch wenn es mit dicitur (403) abgeschwächt wird; vgl. Haupt ${ }^{11} 1969$, 333 (ad met. VI, 412-674)), widerspricht sich schon auf der unmittelbaren Textebene. Zudem weist Cole sogar selbst darauf hin, dass Ovid damit scheinbar der einzige neben Castor sei, der die pelopidische Herrschaft mit Pelops beginnen würde (vgl. Cole 2004, 359f.). Diese Annahme, die allein auf der eigenen Auslegung eines nur bei Ovid bezeugten und anders als in der „Fasten“-Stelle ausgelegten Adjektivs beruht, in der sehr wahrscheinlich nicht Pelops als Herrscher von Mykene gemeint ist, steht somit auf unsicherem Grund. S. o. S. 170, Anm. 17.

Dass die erste und naheliegende Assoziation bei Mykene, das im gleichen Vers mit Argos und Sparta genannt wird, darüber hinaus die mit den Pelopsenkeln Agamemnon und Menelaos ist, ist kaum zu bezweifeln. Rosati ${ }^{2} 2013$, ad met. VI, 412-423, verweist sogar auf die Modellhaftigkeit eines 
stand der Städte Mykene und Messene erweist sich so im Nebeneinander mit Sparta und Troizen als ungültig oder unwahr. Der Eigenschaft von Troizen ist dagegen durch das explizite neque adhuc rundheraus wahr bzw. gültig. ${ }^{24}$ Sparta ist zudem durch seine - in ästhetischen Begriffen - semantische Unvollständigkeit weder auf die eine noch auf die andere Bezugnahme hin eingeschränkt. ${ }^{25}$ Eine innerdiegetische Verbindung zum einen von Sparta und Messene enthält offenbar einen möglichen, zum anderen von einem pelopeiadischen Mykene und noch nicht pittheischen Troizen einen tatsächlichen poetischen Synchronismus, der aber wegen der fehlenden Determination von Pelopeias ebenso wenig klar zur Geltung kommt.

Auf das bisher ausgesparte Nelea Pylos (418), welches mitunter auch als Synchronismus diskutiert wird, ${ }^{26}$ scheint dies gleichermaßen zuzutreffen. ${ }^{27}$ Die Aussage ist auch hier: Das neleische Pylos, zu diesem Zeitpunkt also von Neleus, dem Vater Nestors, beherrscht, schickt seine Gesandten. Neleus wäre damit ein Zeitgenosse Pandions und Pelops'. ${ }^{28}$ Problematisch ist allerdings, dass bereits eine frühere Stelle in den „Metamorphosen“ denselben Neleus in einem klar als früher bestimmbaren Kontext erwähnt. ${ }^{29}$ Denn vom Hirten Battos, den Merkur in einen Stein verwandeln wird, heißt es:

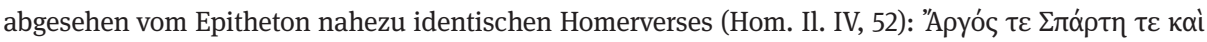

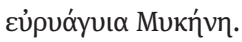

24 S. dazu auch die obigen Überlegungen in Kap. 3.2.2.1.

25 Vgl. Haller 1986b, 75f. Es ist offen für eine Gleichsetzung oder Assoziation mit den anderen prätrojanisch-mythischen Städten aus dem direkten diegetischen Umfeld, weiterhin mit den anderen trojanisch-mythischen Städten Argos und Mykene, die durch die Ähnlichkeit mit dem homerischen Vers und die Aktualisierung bei Pelopeiades aufgerufen werden, sowie schließlich mit der durch die Kriegshandlungen mit Messene evozierten historischen oder zeitgenössischen Perspektive.

Unzureichend muss daher ein Interpretationsansatz sein, der sich auf nur einen dieser Aspekte unter Nichtbeachtung der anderen festlegt.

26 Vgl. Cameron 2004, 285 und Cole 2008, 22.

27 Man könnte sogar sagen, dass dies noch unmittelbarer hervortritt, weil die bereits beobachtete Kennzeichnung neque adhuc (418) bei Troizen im selben Vers steht.

28 S. das Schaubild bei Cole 2004, 393. Dass nach einer anderen, nichthomerischen Überlieferung Neleus sogar der Schwiegersohn von Amphion und Niobe war, weil er die einzige überlebende Niobide Chloris heiratete (vgl. z.B. Hes. cat. Fr. 25 Hirschberger), ist für die „Metamorphosen“ von geringer Bedeutung, weil ,die letzte, die übrig war' (ultima restabat - met. VI, 298) effektvoll in den Armen ihrer Mutter umgebracht wird. Vgl. Bömer ${ }^{2} 2008$, ad met. VI, 299, der aber vor weiteren Rückschlüssen aus dieser Besonderheit, dass das jeweils letzte Kind besonders hervorgehoben wird, mit dem Verweis auf mögliche „poetisch-technische Gründe“ warnt; wenngleich m.E. eine metapoetische Deutung, dass Ovid mit dieser letzten Tochter zugleich auch diesen Überlieferungsstrang für seine eigene Erzählung kappt, durchaus reizvoll ist.

29 Warum Cole diese Stelle weder in seinem Aufsatz noch in seiner Monographie (auch der Index Locorum führt sie nicht) berücksichtigt, bleibt unklar; es bedeutet aber, dass dessen ohnehin z. T. problematischen Schlussfolgerungen bezüglich der zeitlichen Verortung von unter anderem Pelops und Neleus auf einer unvollständigen Berücksichtigung des Textes beruhen und vor dem Gesamtbefund nicht aufrechtzuerhalten sind. Gleiches gilt für Rosati ${ }^{2} 2013,412-423$, der sich direkt auf Cole 
divitis hic saltus herbosaque pascua Nelei

nobiliumque greges custos servabat equarum. ${ }^{30}$

[690]

Die zeitliche Verankerung ist hier zum einen durch den Verweis wenige Verse vorher, dass sich die Geschichte zu genau, jener Zeit‘ (illud erat tempus - met. II, 680) abspielt, mit der vorangegangen Okyrrhoe-Episode verknüpft, ${ }^{31}$ und zum anderen mit dem anschließenden Merkur-Abenteuer bei den Kekropstöchtern in Athen. Neleus ist dieser Aussage zufolge aber ein Zeitgenosse von Kekrops, Okyrrhoe und - über die anderen Synchronismen - sogar von Phaethon und Epaphus. ${ }^{32}$ Des Weiteren stellt der possessive Genitiv von Nelei einen persönlichen Bezug zu dessen Besitz und zu dessen Verwalter Battos her, was noch durch das Beiwort der Pferde als nobilium (690) verstärkt wird, deren Vorzüglichkeit und Bekanntheit - nobilis vereint in sich sehr passend, aber unübersetzbar beide Bedeutungen - von Homer an sprichwörtlich für ihn sind. ${ }^{33}$ Anders als bei dem nur adjektivischen Epitheton im sechsten Buch ist Neleus hier also persönlich und über Attribute, die traditionsgemäß mit ihm in Verbindung gebracht werden, repräsentiert. Für das spätere und in seiner Assertion schwächere Nelea (met. VI, 418) ist diese frühere und definitivere Information zu Neleus notwendigerweise miteinzubeziehen, Letztere ist folglich ein Anachronismus. ${ }^{34}$

Zusammenfassend hat sich also bei jenem Städtekatalogs im sechsten Buch herausgestellt, dass bei eigentlich allen Epitheta, sofern nicht als Prolepsen ausgewiesen, ein zeitlich problematischer Aspekt in Bezug auf das unmittelbare diegetische Geschehen zum Vorschein kommt: Mykene ist nicht pelopeiadisch, Korinth nicht erzberühmt, Messene nicht wild und - wenn man den expliziten Informationen des

beruft und in seiner Deutung der Passage, die vor allem das Homerische des Katalogs herauszustellen bestrebt ist, die meisten Aktualisierungen im Einzelnen gar nicht erwähnt bzw. erklärt (Pelopeias, obwohl in mehrerlei Hinsicht erklärungsbedürftig, wird z. B. gar nicht behandelt).

30 Met. II, 689f.: ,Dieser hütete als Wächter die Waldschluchten und die grasreichen Weiden des reichen Neleus und die Herden seiner vortrefflichen Pferde.‘

31 Vgl. zu dieser Zeitangabe im Kontext des zweiten Buches Keith 1992, 95 f.

32 Möglicherweise fand sich die Verbindung von Hermes' Rinderdiebstahl mit Pylos schon bei Nikander oder einem Gelehrten aus dieser Zeit. Vgl. Holland 1926, 158.

33 Vgl. Bömer 1969, ad met. II, 689.

34 Denn dies würde andernfalls bedeuten, dass Neleus von Kekrops' Zeit an sieben Generationen lang herrscht, um auch noch ein Zeitgenosse Pelops' und Pandions zu sein.

Wohl eher könnte ein solches Alter auf seinen Sohn Nestor zutreffen, der sich bekanntlich ein übertrieben langes Alter zuerkennt, sodass er seinen Vater wirklich hätte treffen können. Es ist zumindest theoretisch möglich, da zu den sieben oder acht Generationen bis zu Kekrops noch die zwei zusätzlichen von Pandion über Aigeus zu Theseus, der dann der Zeit des trojanischen Krieges angehört, hinzukämen. S. dazu die Tabelle bei Cole 2004, 368f. Allerdings ist es naheliegender, dies bei Nestor vornehmlich damit zu erklären, dass seine Aussagen eine ganz eigene Wahrheit haben. S. o. Kap. 5.1.1.1c. Nebenbei bemerkt berücksichtigt Cole auch die Stelle in met. VIII, 313 nicht, obwohl sie sowohl für die innere Chronologie der „Metamorphosen“ durch den Erzählerverweis etiamnum sehr aussagekräftig ist (s.u. S. 178f., Anm. 49) als auch Coles eigene Systematik entschieden infrage stellen würde. 
Erzählers folgt - Pylos eben auch nicht neleisch, als es zu jenem Zeitpunkt geboten war, eine Gesandtschaft nach Theben zu schicken. ${ }^{35}$ Vor diesem Hintergrund kann überdies mit Recht bezweifelt werden, dass Orchomenos und Kleonai genau „damals“, also zur Zeit der fiktiven Trauer in Theben, in einem solchen Zustand waren, dass sie ferax (416) und humiles (417) genannt hätten werden können. ${ }^{36}$

\subsubsection{Zeitbezug vs. Weltbezug}

So drängt sich die Frage auf, ob diese Beiworte überhaupt auf eine solch direkte Weise zur zeitlichen Verortung der Handlung herangezogen werden dürfen und für die Rekonstruktion einer Genealogie mitsamt synchronistischen Beziehungen brauchbar sind. ${ }^{37}$ Unabhängig davon, ob diese Aktualisierungen dann anachronistisch, synchronistisch oder lediglich ambivalent wären, stehen sie auf gleicher logischer Ebene. ${ }^{38}$

Erkenntnisreich ist deshalb das ihnen unmittelbar entgegengesetzte Verfahren der Anachronie. Denn erst der Zusatz von nondum (415) neque adhuc (418) scheint den zeitlich sonst merkmallosen Adjektiven - merkmallos hinsichtlich der konkreten Beschaffenheit der erzählten Welt - dann eine Merkmalhaftigkeit zuteilwerden zu lassen. Dieses „detachment of the narrator“339 mittels nondum oder Ähnlichem, das die temporale Struktur des Gedichts konsolidiert und auch eine gewisse Erwartung auf das noch Eintretende weckt, hat so gesehen noch einen weiteren konsolidierenden Effekt: Es legt die meist allgemeine und unspezifische Zeitrelation bei einem Attribut,

35 Dass auch die formale Struktur des Katalogs, die in diesem Fall als ein „erratic pattern“ mit wechselnder Anzahl an Namen im Vers zu klassifizieren ist, die Textaussage unterstreichen kann, wird ersichtlich bei Kyriakidis 2007, $50 \mathrm{f}$.

36 Hinzuzufügen ist, dass aus heutiger Sicht nicht mit absoluter Sicherheit gesagt werden kann, welche Städte Ovid hier meint und was humilis exakt bedeutet. Vgl. Bömer ${ }^{2} 2008$, ad met. VI, 416 und 417.

37 So liest Hardie 2015, ad met. XV, 296, dann das unmarkierte Pittheam ... Troezena (met. XV, 296) aus dem Munde von Pythagoras als Zeitangabe („Pitagora postdata Pitteo“), die einen „anacronismo“ darstelle. Im Prinzip aber kommen diesem Problem Cole mit dem „ecphrastic mode“ (Cole 2004, 411) oder Bömer mit jenem schillernden „Zusatz ex persona poetae“ (s. o. Kap. 4.1.3) schon sehr nahe; obschon diese Beobachtung für alle nicht-anachronistischen, nicht-aktualisierenden Fälle ebenso diskutiert werden müsste.

38 Schon aufgrund dieser prinzipiellen Gleichwertigkeit ist es aber unzulässig, das eine Detail bei Pylos als signifikanten Zeitbezug herauszuheben, ohne auch die Implikationen der anderen Epitheta in derselben Weise zu berücksichtigen. Umgekehrt ist dies bei Haupt ${ }^{11} 1969,334$ f., wo bei Mykene, Korinth und Messene auf den Beinamen aufmerksam gemacht wird, „den sie zur Zeit der geschilderten Begebenheiten nicht führen“ (ad met. VI, 414); aber bei Pylos und den anderen Städten nicht.

39 S. dazu Solodows sehr passende Bemerkungen zu Zusätzen wie nondum und Futurpartizipien, „which refer to the future by stating not what will happen, in positive terms, but what has not yet happened. These are only a roundabout form of the other, and they equally signal the existence and the detachment of the narrator“ (Solodow 1988, 63). Darin übereinstimmend spricht auch Bömer gelegentlich bei solchen Partizipien von „Zusatz ex persona poetae“, vgl. Bömer 1969, ad met. I, 55. 
deren Ambivalenz in poetischer Sprache meist nicht weiter aufgehellt werden muss oder sogar anschlussfähig für eine kreative Aneignung ist, auf eine einzige und konkrete Relation fest.

Allgemein und zunächst ohne den spezifischen Kontext betrachtet, könnte dies folgendermaßen am Beispiel Troizens erläutert werden: Wenn dieses Troezen mit Pittheia attribuiert wird, ist es auf jenen Heroen Pittheus bezogen. Welche Beziehung allerdings über die Verknüpfung von Adjektiv und Nomen genau hergestellt wird, d. $h$. was ,pitthëisch' (Georges) oder , of or belonging to Pittheus' (OLD) dann konkret ausdrückt, muss aber, wie die vagen Bedeutungsangaben offenbaren, aus seinem unmittelbaren Kontext erschlossen werden - etwa ob es zu seinem Bezugswort in verwandtschaftlichem, besitzanzeigendem oder nicht näher ermittelbarem logischen Verhältnis steht, das damit modelliert wird. ${ }^{40}$

Eine Besonderheit in temporaler Hinsicht - und das ist hier das Entscheidende ist es nun, dass die zeitliche Referenz, die diese Attribuierung eines Adjektivs zu seinem Nomen impliziert, per se limitiert ist auf einen Bereich maximal bis zur Gegenwart der Äußerung. Denn allein der Umstand, dass einem Bezugswort Troezen diese Eigenschaft Pittheia zugeschrieben wird, impliziert schon, dass der Anlass für diese Zuschreibung entweder gegenwärtig vorliegt oder zuvor vorgelegen hat und noch immer gültig ist. Prinzipiell kann Pittheia Troezen also keinen zukünftigen Status zum Ausdruck bringen, die Prädikation des Adjektivs ist immer: ,Troizen ist pitthëisch bzw. war es, ist es aber in einer kontextuell relevanten Weise immer noch'; aber niemals kann es als Pittheia Troezen diese Eigenschaft erst noch erlangen. Und weil das für jede adjektivische Attribution gilt, kann ein futurischer Aspekt in einer solchen Nominalphrase nur zum Ausdruck gebracht werden, wenn entweder die adjektivische Prädikation selbst mit einem zusätzlichen Attribut modifiziert wird - z.B. durch nondum oder neque adhuc - oder das Adjektiv diese futurische Bedeutung bereits in sich trägt - im Lateinischen als Partizip Futur Aktiv. ${ }^{41}$ Eine solche Modifikation leistet dabei zweierlei: zum einen erweitert sie auf syntaktischer Ebene in diesem Nominalgefüge die ursprüngliche Beziehung zwischen Adjektiv und Nomen, indem sie sie an diejenige Bedeutung anpasst, die vom jeweiligen Zusatz ausgedrückt wird: ,Troizen ist pitthëisch' wird z. B. mit dem Zusatz von neque adhuc zu ,Troizen ist pitthëisch noch nicht ${ }^{6}{ }^{42}$ zum anderen macht sie eine sprecherseitige Intervention kenntlich, bei

40 Vgl. Fleischer/Barz ${ }^{4}$ 2012, wo in Bezug auf die von Eigennamen abgeleiteten Adjektive auf „-isch“, das in etwa dem griechisch-lateinischen Suffix -eius/-eus/-ius entspricht, von „unspezifischen relativen Adjektiven“ (317) die Rede ist, wobei „relativ“ bedeutet, dass sie als Adjektiv eine relationale Bedeutung (,steht in Verbindung mit‘) gegenüber ihrem Bezugswort haben. Vgl. auch de Melo 2019, 124 (zu -ius): „derives broadly possesive adjectives from nouns“.

41 Letzteres ist allerdings bei Pittheia als einem adjektivischen Derivat eines Eigennamens wie auch bei Adjektiven, die eine beständige Eigenschaft ausdrücken wie z. B. ferox und humilis, nicht möglich. Es ist aber kein Zufall, dass Bömer und Solodow diese beiden Verfahren, zusätzliches adverbiales Attribut und Partizip Futur, unter demselben Vorzeichen diskutieren.

42 Diese Modifikation kann neben temporalen Aspekten auch jede vom Sprecher intendierten und in Bezug auf das Adjektiv möglichen Aussagen ergänzen: Abstufungen, persönliche Wertungen etc. 
der zugleich auch der zeitlich-epistemische Standort des Sprechenden zum Vorschein kommt. ${ }^{43}$

Übertragen auf den Aussagekontext der „Metamorphosen“ heißt das zunächst, dass bei neque adhuc Pittheia Troezen (418) die präsentische Bedeutungsrelation des Nominalgefüges Pittheia Troezen blockiert und deutlich von der diegetischen Umgebung in ihrer zeitlichen und örtlichen Determination, Theben zur Zeit des Pelops, abgesetzt ist. Für die Diegese gilt allein: neque adhuc Pittheia Troezen. Die Differenz zum unmittelbaren Kontext ist daher bei dieser Modifikation des Adjektivs - im Gegensatz zum nichtgekennzeichneten Normalfall - explizit festgehalten und bedarf keiner Auslegung.

Indem nun aber Ovid seine scheinbar neutrale, merkmallose Erzählhaltung verlässt und sich als ordnende, extradiegetische Instanz zu erkennen gibt, wird zugleich auch eine fundamentale Eigenschaft der Erzählsituation überhaupt kenntlich. Allen Aussagen dieses Primärerzählers wohnt eine doppelte zeitliche Implikation inne: die für die diegetische Welt, und eine, die für die extradiegetische Welt relevant ist. Bei der Aussage Pittheia Troezen wird aber in einer konventionellen Rezeption die volle und unterschiedslose Geltung der Implikation in beiden Welten angenommen und der epistemische Unterschied zwischen extradiegetischem Erzähler und diegetischer Handlung als zu vernachlässigen angesehen. ${ }^{44}$ In Folge dieser Annahme kommt deshalb die in jener Nominalgruppe festgelegte Gleichzeitigkeit - pitthëisch in Bezug auf Troizen als ein gegenwärtiger Zustand - auf diese zweifache Weise voll zum Tragen, wenn sie nicht zusätzlich von Seiten des Erzählers markiert wird. ${ }^{45}$

Die Auflösung dieses Nebeneinanders aus zeitlich indifferenter, extradiegetischer Zuschreibung und zeitlich signifikanter Beschreibung einer fiktiven Realität durch den Kommentar neque adhuc kehrt damit auch die eigentliche Erzähl-Hierarchie nach außen: Das vom extradiegetischen Erzähler geäußerte Pittheia Troezen erweist sich für den diegetischen Kontext als mittelbar, wenn es nur mehr mit Einschränkung geäußert werden kann. Dagegen bleibt der nicht-diegetische und damit auch nicht von einer Erzählinstanz abhängige Aspekt, dass Pittheus in einer Verbindung mit Troizen steht, in ungeminderter Weise bestehen und erweist sich in dieser Hinsicht als unmittelbar und der konkreten diegetischen Bedeutung übergeordnet. ${ }^{46}$

Der strukturierenden Hierarchisierung anhand von Eingriffen des Erzählers entgegengesetzt ist im Städtekatalog die Nennung von Argos, Sparta und Patrai. Wegen des Fehlens eines Epithetons oder sonstiger zusätzlicher Charakteristika sind sie

43 In genau dieser Hinsicht ist Solodows Äußerung über „,the existence and the detachment of the narrator“ bei nondum u.ä. zu verstehen. S. o. S. 174, Anm. 39.

$44 \mathrm{Zu}$ Aristoteles s. o. S. 166, Anm. 211. Zu Vergil s. Heinze ${ }^{8} 1995,370$ - 373.

45 Vgl. auch Tronchet 1998, $169 \mathrm{f}$.

46 Auf gleiche, nur lexikalisch verschiedene Weise geschieht dies anhand von nondum (415) bei Kalydon. Auch hier wird die über das Attribut ausgedrückte Bedeutung, Dianas Missgunst gegenüber Kalydon, in Bezug auf die Diegese revidiert, bewahrt außerhalb davon aber ihre Gültigkeit als literarisch tradiertes Mythem. 
überhaupt nicht festlegbar, weder hinsichtlich des diegetischen Umfeldes noch gegenüber dem extradiegetischen Standpunkt. Dadurch bereitet es keinerlei Probleme, bei ihnen einerseits die für den Handlungskontext notwendigen Eigenschaften ergänzend hinzuzudenken, vor allem, dass es sich um Städte handelt, die zu Lebzeiten von Pelops und Pandion eine gewisse Handlung vollziehen; andererseits hindern diese semantischen Leerstellen den Rezipienten bei Argos und Sparta nicht daran, auch an deren viel zentralere Rolle im Umfeld des trojanischen Krieges zu denken, besonders in Nachbarschaft mit dem Pelopeiadesque Mycenae sowie durch die Parallele mit jenem nahezu identischen Homervers. ${ }^{47}$

In einem als Linie $\mathrm{zu}$ imaginierenden Bedeutungsspektrum von zeitlichen $\mathrm{Zu}$ schreibungen und ihrer doppelten Referenz auf einen diegetischen und einen extradiegetischen Wissensbereich könnte man die bisherigen Beobachtungen folgendermaßen einordnen: Grenzt man es an seinen Rändern jeweils durch die zwei vorliegenden Extreme ab, so ist an der einen, minimal festgelegten Stelle die bloße Nennung der Städte ohne weitere Charakteristika verortet und am anderen, maximal determinierten Rand die mittels Erzählerkommentar erfolgte Strukturierung der Aussage hinsichtlich ihrer Bedeutung in der Diegese. Im einen Fall - dem der maximalen Strukturierung - ist ein direktes In-Beziehung-Setzen der Information auf das diegetische Geschehen durch den Zusatz z.B. von nondum ausgeschlossen, im anderen - dem der minimalen Festlegung - ist die Information dagegen wenig eingrenzbar und kann folgerichtig auch keine Bezugnahme ausschließen, zu der der unmittelbare Kontext einerseits und der jeweilige Rezeptionskontext andererseits auffordern mag.

Geht man von diesen so gesteckten Koordinaten weiter und fragt nach der Verortung der noch verbleibenden Beispiele des Katalogs - Pelopeiades Mycenae, Orchomenos ferax, nobilis aere Corinthus, Messene ferox, humiles Cleonae und Nelea Pylos -, ist zunächst offensichtlich, dass sie weder vollständig zur einen Seite der minimalen Festlegung gerechnet werden können, weil sie um ein Attribut erweitert und somit weiter spezifiziert sind, noch zur anderen mit der definitiven extradiegetischen Hierarchisierung, weil eine zusätzliche temporale Markierung nicht vorliegt. Demnach wird die eben beobachtete, gewissermaßen naive Annahme, die Aussagen mitsamt ihren zeitlichen Implikationen vollgültig auf das diegetische Umfeld beziehen zu können, insofern nahegelegt, als sie nicht durch Gegenteiliges widerrufen wird.

Und wie um diese sozusagen natürliche Rezeptionsweise $\mathrm{zu}$ bestätigen, sind manche dieser Epitheta - gemeint sind ferax (416) und humiles (417) - unverfänglich

47 S. o. S. 171f., Anm. 23. Für einen Zeitgenossen Ovids könnte darüber hinaus auch Patrai eine aktuelle Assoziation hervorgerufen haben: Patrai hat in augusteischer Zeit die Herrschaft über Kalydon und dessen Territorium gewonnen und im Zuge dessen sind auch die Kultbilder der Artemis von Kalydon dorthin überführt worden.Vgl. Strauch 1999, 212. So könnte hier das in der Diegese noch nicht der Diana/Artemis verhasste Kalydon noch um das künftige, nicht mehr mit dem Artemis-Kult zusammenhängende Kalydon ergänzt werden, bestärkt durch den Kontrast zu Patrai, der so gesehen recht neuen, zeitgenössischen Kultstätte. 
gegenüber der diegetischen Umgebung, weil sie Charakteristika ausdrücken, die nur schwerlich den Stand einer konkreten historischen oder genealogischen Entwicklung anzeigen. ${ }^{48}$ Die diesbezügliche Merkmallosigkeit ihrer Attribute rückt Orchomenos und Kleonai damit in die Nähe der semantisch minimal determinierten Städte Argos, Sparta und Patrai. Anders die übrigen Epitheta, sie repräsentieren einen Zustand, der weniger dem der Diegese als gänzlich dem des extradiegetischen Erzählerwissens entspricht, und sind deswegen in ihrem Zeitaspekt an die Seite jener markierten Aussagen bei Kalydon und Troizen zu stellen. Weil sie sich aber formal weder von den unspezifischen attribuierten noch von den gänzlich merkmallosen Städten unterscheiden, in dieser Hinsicht sogar die Gemeinsamkeit teilen, von jenen mit nondum o. ä. markierten Aussagen verschieden zu sein, wird bei ihnen - eben anders als bei einer Markierung - gleichermaßen eine vermeintliche Merkmalosigkeit impliziert.

Interessant an diesen Epitheta ist daher, dass sie von ihrer Form her vorgeben, merkmallos zu sein, aber eigentlich eine Einschränkung von Seiten des Erzählers benötigen, die genau diese Implikation blockiert und darauf hinweist, dass z. B. Korinth zum gegenwärtigen Stand der Erzählung noch gar nicht für seinen Erzreichtum bekannt ist. Ein solches Nominalgefüge ist folglich ein Hybrid aus formaler Merkmalosig- und zeitlich-inhaltlicher Merkmalhaftigkeit.

\subsubsection{Epitheta ornantia als extradiegetische Zuschreibungen}

Wenn über eine konventionelle Attribuierung oder Zuschreibung eines fiktiven Objektes ein Zeitbezug gegenüber dem diegetischen Geschehen impliziert wird, dann scheint der zeitliche Aspekt nur dann auf dieses Geschehen bezogen werden zu dürfen, wenn der Erzähler diesen als in den diegetischen Grenzen signifikant ausweist. ${ }^{49}$ Deswegen ist es für diesen Vorgang, verstanden als sprachlogische Modi-

48 Wenn man humilis geographisch liest, wie es vorgeschlagen wird bei Haupt ${ }^{11} 1969$, ad loc. und Bömer ${ }^{2} 2008$, ad loc. Zudem wäre auch Mopsopios (423) als Beiwort zu muros mit dem heute verfügbaren Wissen hierzu zu zählen, das mutmaßlich auf einen athenischen Heros oder König Mopsopos, Mopsops oder Mopsos (oder eine Okeanide namens Mopsopia, vgl. Wrede 1933) zurückgeht, über dessen Existenz man jedoch nur weiß, weil der alte Name Attikas „Mopsopia“ wohl auf ihn zurückgeht. Vgl. Antoni 2000. Der Name selbst ist erst ab dem Hellenismus (z. B. Lykoph. Alex. 733 (Мóభолоৎ) und 1340 (Мофолві́оч)) belegt.

49 Weitere Beispiele, in denen explizit die zeitliche Geltung eines Attributs auf das in der Diegese gegenwärtige Geschehen hin modifiziert wird, finden sich für nondum in met. II, 219: nondum Oeagrius Haemus; met. VII, 232f.: gramen/ nondum mutato vulgatum corpore Glauci; met. VIII, 372: gemini, nondum caelestia sidera, fratres; met. XIV, 157: litora adit nondum nutricis habentia nomen. Für neque/ nec adhuc ist Pittheia Troezen das einzige Beispiel. Für bloßes adhuc beim Adjektiv finden sich zahlreiche Beispiele, von denen am aussagekräftigsten sind met. VIII, 316f.: et adhuc a coiniuge tutus/ Oeclides; met. IX, 407: vivus adhuc vates; met. XIV, 562: cladis adhuc Phrygiae memores. Die Liste ließe sich problemlos mit Beispielen anderer Zeitadverbien erweitern - wie u. a. nunc (z. B. met. II, 649: nunc immortalis), modo (z.B. met. XIII, 508: modo maxima rerum - allerdings auch auf das Prädikat beziehbar), tandem (z.B. (sogar in Verbindung mit Futurpartizip) met. II, 222: tandem nivibus caritura Rhodope), nuper (z. B. met. III, 213: Hylaeusque fero nuper percussus ab apro), iam non (z. B. (in Bezug 
fikation, zunächst auch bedeutungslos, welchen Realitätsbezug solchermaßen attribuierte Objekte genau haben, d. h. ob sie wie die Orte in jenem Städtekatalog real oder pseudo- oder nicht-real sind. Denn das, was über einen Zusatz wie neque adhuc modifiziert wird, ist nicht das fiktive Objekt selbst wie hier Troezen, sondern das es als Pitthea attribuierende und Gleichzeitigkeit implizierende Epitheton. ${ }^{50}$ Schließlich ist es eine Notwendigkeit des Handlungsgeschehens, dass eine fiktive Entität mit dem Namen Troezen eine gewisse Tätigkeit, konkret: eine Trauerbekundung, ausübt. In keiner Weise wesentlich ist hierfür allerdings, mit welchen zusätzlichen Erkennungsmerkmalen diese Entität vom Erzähler ausgestattet wird - mag sie nun pitthëisch, mit breiten Straßen versehen oder von erzgewandeten Männern bewohnt sein. ${ }^{51}$

Umgekehrt heißt das aber: Bleibt es nur bei einer Implikation wie bei Nelea Pylos, dann dient das Attribut und die in ihm liegende Implikation nicht der Beschreibung der konkret vorliegenden fiktiven Realität, sondern ist eine überzeitliche, vom extradiegetischen Erzähler stammende Ergänzung zu dem in der Diegese genannten und darin handelnden Objekt. ${ }^{52}$ Demzufolge impliziert Nelea Pylos zwar die Bedeutung, dass Pylos gegenwärtig nelëisch, also unter der Herrschaft von Neleus ist, sie bleibt dieser gegenüber aber indifferent und sagt nichts über die gegenwärtige Beschaffenheit des damit attribuierten Objektes Pylos aus. Dass diese Implikation eine Eigenschaft ausdrücken kann, die auch auf die konkret vorliegende diegetische Entität zutrifft, ist deswegen keineswegs ausgeschlossen..$^{53}$ Ovid scheint dies mit den genannten Mitteln sogar mehrfach herauszufordern.

auf ein Substantiv) met. VIII, 305: iam non femina Caeneus) oder etiamnum (z. B. bei Nestors Altersangabe; s. o. Kap. 5.1.1.2c). Es ist aber augenfällig genug, wie durch die Modifikation der adjektivischen Attribution die in ihr implizierte Gleichzeitigkeit von Adjektiv und Nomen auf das konkrete diegetische Umfeld bzw. die situative Einbettung des Sprechaktes hin bezogen wird. In manchen, aber keineswegs allen Fällen handelt es sich dann sogar um Verweise auf spätere, in den „Metamorphosen“ selbst noch berichtete Begebenheiten, z. B. bei Orpheus, Glaukos und Kaineus.

50 Wie relevant diese Beobachtung für den Anachronismus ist, zeigt sich bereits an früherer Stelle. S. o. Kap. 5.1.1.

51 Schon die homerischen Epitheta zeigen diesen paradoxen Wesenszug: Nausikaa will z. B. die in

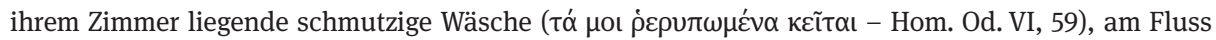

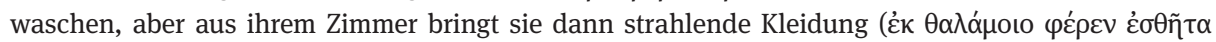

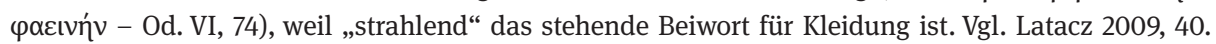
Inwiefern die Spezifik der ovidischen Epitheta mit deren grundsätzlichen Verwendung im antiken Epos zusammenhängt, kann an dieser Stelle nicht eingehender beschrieben werden; wie das Homer-Beispiel aber zeigt, können Epitheta von den frühesten Belegen an sowohl selbst als auch in ihrem Bezug auf das Handlungsgeschehen semantisch verblasst sein und gegenüber dem Kontext fundamental widersprüchlich erscheinen. Vgl. dazu grundsätzlich Leumann 1950, 27-34 und Latacz 2009, 53 f.

52 Dies spiegelt sich auch auf logischer Ebene, da Implikationen einerseits wahrheitsfähig sein können, aber umgekehrt, weil sie es nicht sein müssen, keine Wahrheit absolut aus ihnen geschlossen werden kann. Vgl. Haller 1986a, 48f. und Mácha 2010, 89 f.

53 Es wäre aber grob ungenau, daraus im Umkehrschluss eine situative Richtigkeit - d. h. Übereinstimmung von Implikation und tatsächlichem Zustand in der erzählten Welt - als Beweis für den prinzipiellen Wahrheitswert dieses Aussagemodus zu sehen. 
Aber nicht nur die eklatant unzutreffenden Zuschreibungen wie beispielsweise bei Korinth durch nobilis aere (416) offenbaren die Unzulänglichkeit der Annahme, die Informationen des Erzählers rundheraus für historisch zu halten, sondern sie lässt sich letztlich schon durch die in dieser Textpassage mit Sicherheit verfolgte Intention validieren, einen synchronistischen Übergang von den Ereignissen in Theben zu denen in Athen herzustellen. Die Synchronizität von Pelops und Pandion ist das logische Fundament dieser Verknüpfung und wäre nicht unwesentlich beeinträchtigt, wenn seine Plausibilität in irgendeiner Weise gemindert wird.

Angenommen aber, man versteht Mopsopios muros (423) positivistisch als ,die Mauern des Mopsopos o.ä.', könnte dies - je nach Auslegung des Attributs und des Wortes muros - als zeitlich unvereinbar mit dem Synchronismus Pelops-Pandion gesehen werden. Wahrscheinlicher aber ist - nahegelegt auch durch terrebant, dessen Objekt im Normalfall Lebewesen sind -, dass die Mauern pars pro toto für die Stadt stehen und Mopsopios muros eher die ,Mopsopische Stadt' meinen, die vom feindlichen Heer in Schrecken versetzt wurde. ${ }^{54}$ So könnte die zeitliche Implikation, die von diesem Attribut ausgeht, hier ebenso lauten - wenn auch abgeschwächt wegen der Teil-Ganzes-Beziehung bei muros -, dass ein gewisser, vermutlich als Mopsopos zu bezeichnender Mann der Herrscher oder ein irgendwie maßgeblicher Mann dieser Stadt sei. Und bezogen auf den gegenwärtigen, diegetischen Zustand Athens, stünde dies in deutlichem Widerspruch zur Regentschaft des Pandion, der sogar explizit als Herrscher ausgewiesen wird (claro Pandione tyranno - 436), und liefe somit der hauptsächlichen Absicht dieser Überleitung entgegen.

Auch die Erfordernisse der Erzählung stützen somit die Schlussfolgerung, dass die zeitliche Relation, die über ein Epitheton impliziert wird, primär nichts über die konkrete Verfassung der diegetischen Umgebung aussagt. ${ }^{55}$ Das Interessante an der ovidischen Verwendung ist daher, dass dieser Eindruck mittels der genannten kontrastiven oder zeitlich unproblematischen Verfahren sehr wirkungsvoll evoziert wird.

Formal betrachtet nutzt Ovid dafür lediglich das im Kern schon bei den homerischen Epitheta vorhandene Auseinanderklaffen zweier Zeitbezüge. ${ }^{56}$ Besonders in den „Metamorphosen“ ist aber, dass dieses Konfliktpotenzial noch offensiver in den Vordergrund rückt, weil die Epitheta - selbst ein Resultat eines historisch-genealogischen

54 Sicherlich ist hier einzuwenden, dass Mopsopios wohl selbst für einen gebildeten Römer kaum mehr als ,attisch' bedeutet haben mochte und die dahinterstehende Person, Mopsopos o.ä., in historischem Sinn gänzlich verblasst und auch nicht als Errichter der Mauer bekannt war, doch um der Illustration willen sei der Gedanke in seiner ganzen Konsequenz hier einmal zu Ende gedacht.

55 Weitere Beispiele sind u. a. met. II, 219 virgineus Helicon, womit nicht gemeint sein kann, dass zum Zeitpunkt der Handlung, Phaethon hat gerade die Welt in Brand gesteckt, sich die neun Musen, wegen der der Berg ,jungfräulich‘ genannt wird, dort aufhalten. Auch hier steht bezeichnenderweise noch im selben Vers das mit nondum modifizierte Nominalgefüge Oeagrius Haemus; oder der Blick während Medeas Flug auf die antiquae Cartheia moenia Ceae (,die kartheischen Mauern des alten Keos` - met. VII, 368), obwohl für die Insel Keos dieser zeitliche Aspekt fragwürdig ist bzw. „keine besondere Veranlassung zur Verwendung dieses Epithetons“ (Bömer ${ }^{2} 2008$, ad loc.) vorliegt.

56 Zu einem Überblick mit weiteren Beispielen s. Latacz 2009, 39-42. 
Prozesses - gegenüber dem innerdiegetischen Verlauf der Zeit, welcher den Anschein erweckt, tatsächlich eine Nachbildung dieses historisch-genealogischen Prozesses zu sein, ein gleichzeitiges Verhältnis herstellen. Die eigentlich überzeitlich zu verstehende Eigenschaft eines Epithetons wie Nelea bei Pylos kann so gewissermaßen historisch eingeengt und auf den diegetischen Kontext bezogen werden. Weil diese Gleichzeitigkeit aber nur in einer ebenso überzeitlichen, weil logisch privilegierten Erzähler- oder Rezipientensicht Bestand hat, durch die bzw. für die sie auch getätigt wird, basiert sie auf einer Vorwegnahme bzw. Aktualisierung, die nur im Optimalfall gegenüber dem tatsächlichen Stand der Diegese zutreffend ist.

Indem Ovid das Epitheton sozusagen pseudo-historisiert, d. h. dadurch den trügerischen Schein erweckt, eine zutreffende, in diesem Sinn historische Beschreibung einer Welt zu sein, macht er gerade an solchen Fällen, wo sich dies als irrtümlich herausstellt, dessen Künstlichkeit offenbar. Weil gerade dies den fiktionalen vom faktualen Erzähler unterscheidet, lässt sich damit auch bestätigen, dass Epitheta jenes für Anachronismen und Aktualisierungen erforderliche logische Beziehungsgefüge aufweisen: ${ }^{57}$ Ein fiktives Objekt - hier bei den Städtenamen reale bzw. pseudoreale Objekte - wird in seiner diegetischen Umgebung als pseudo-real ausgewiesen, weil es mit Charakteristika versehen ist, die den originären Realitätsbezug einschränken - hier einerseits als reales Objekt, das geographisch identifizierbar ist, das andererseits aber als von einer langen literarischen Tradition etabliertes pseudoreales Objekt in Erscheinung tritt, wo es Schauplatz anderer fiktionaler Narrative ist. Ein ohnehin schon pseudo-reales Objekt Nelea Pylos, das diesen Namen einer mythischen, in dieser Form nicht-realen Figur verdankt, impliziert somit durch seine vom Erzähler nicht gekennzeichnete Darbietung, dass zu der Zeit $t$ eine Prädikation der Eigenschaft $F$ auf das Objekt $a$ zutrifft, also gleichzeitig ist mit dem fiktiven diegetischen Geschehen. Als Aussage des extradiegetischen Erzählers ist Nelea Pylos faktual für die Diegese - sie wird schwarz auf weiß geäußert -, die Implikation, dass die Aussage den konkreten diegetischen Zustand auch beschreibt, ist dagegen fiktional, weil sie auf der epistemischen Ungleichheit zwischen Erzähler und erzählter Welt beruht und nicht für die erzählte Welt auf dieselbe Weise gilt wie für den außerhalb davon stehenden Erzähler oder Rezipienten.

Pelopeiadesque Mycenae (414), nobilis aere Corinthus (416), Messene ferox (417) und - nach der hier verfolgten Argumentation - Mopsopios muros (423) sind daher poetische Synchronismen und im Prinzip können alle Epitheta, sofern sie das Resultat einer identifizierbaren zeitlichen oder kulturellen Entwicklung sind, hierfür infrage kommen. Sie entstammen der Sicht des extradiegetischen Erzählers und müssen nur in einer solchen Weise als merkmalhaft in Erscheinung treten, dass implizierte Aussage und diegetisches Umfeld einander widersprechen. Andernfalls ist die attribuierte Eigenschaft merkmallos - wie bei Orchomenos ferax (416) und humiles Cleonae (417) -

57 S. o. Kap. 3.3.1f. 
und hebt sich nicht von all den anderen, auf dieselbe extradiegetische Weise mitgeteilten Informationen über die erzählte Welt ab. ${ }^{58}$

Doch ungeachtet dessen, ob die Implikation eines Epithetons in diesem Sinn merkmalhaft, d. h. syn- oder anachronistisch ist oder unauffällig bleibt, repräsentieren die Adjektive erst dann einen Entwicklungsstand eines Objektes in der fiktiven Welt, wenn ihre Zeitrelation durch ein zusätzliches Attribut modifiziert und für diese Welt festgelegt wird. Ohne dies bleibt es bei einer Implikation, die sich nur bestenfalls bewahrheitet, ${ }^{59}$ aber oftmals als trügerisch erweist.

\subsubsection{Abschließende Beobachtungen zu met. VI, 412-423}

Ovid leitet seine Theben verlassende Erzählung synchronistisch nach Athen über, indem er sie mit Anachronien, Aktualisierungen und poetischen Synchronismen, einem Anachronismus und zudem mit weiteren unverfänglichen zeitlichen Implikationen ausstattet. ${ }^{60}$ Zwischen Pelops und Pandion, die es miteinander zu verknüpfen gilt, stehen so als einzige sichere Datumsangaben die beiden Informationen, dass zum einen das Ereignis, das die Jagd auf den Kalydonischen Eber auslöst, noch nicht stattgefunden hat und Pittheus zum anderen noch nicht Troizen regiert.

Eine Antwort auf die Frage, warum gerade diese beiden Städte zeitlich festgelegt werden, liegt bei ersterer auf der Hand, da sich Kalydon und die dort traditionell vor dem trojanischen Krieg stattfindenden Ereignisse generell sehr gut dafür anbieten und zudem ein intratextueller Bezug zu der noch folgenden Schilderung im achten Buch möglich ist. ${ }^{61}$ So bietet sich dem Leser nicht nur ein Orientierungspunkt für den Stand der erzählten Welt, sondern auch für die Erzählung selbst. Eine ähnliche Absicht hinter der Modifikation bei Pittheia Troezen dürfte daher nicht unwahrscheinlich sein. $\mathrm{Zu}$ einer Fixierung der unmittelbaren genealogischen Abfolge trägt es allemal bei, wenn Pittheus in die Generation nach Pelops und Pandion verortet wird, worauf sich dann wiederum im achten Buch der intradiegetische Bericht des troizenischen Helden Lelex (Troezenius heros - met. VIII, 567) stützen kann. ${ }^{62}$ Bedeutender aber dürfte hier sein, dass mit der - zusätzlich extradiegetisch verifizierten - Betonung der Linie

58 Bei Nelea Pylos kommt noch hinzu, dass die zeitliche Implikation des Attributs durch die vorherige Erwähnung von Neleus im Zusammenhang mit Battos von einer epistemisch gleichwertigen Aussage negiert wird und deswegen ein Anachronismus vorliegt. Zur Besonderheit bei subvecta ponto (422) s. o. Kap. 5.1.1.1.

59 Wie in met. VI, 70, wo Athene im Wettstreit mit Arachne auf ihrem Web-Erzeugnis die Akropolis Cecropia arx nennt und dies damit übereinstimmt, dass Kekrops der Tradition nach der Schiedsrichter bei dem Streit zwischen Athene und Poseidon um die Schirmherrschaft der Stadt war. Indes kann Cecropia mit Bömer ${ }^{2} 2008$, ad loc., schlicht auch als ,athenisch“ verstanden werden.

60 Auch vor diesem Hintergrund haben die Zweifel, wie sie Schmidt 1991, 124-126, zu dieser Stelle äußert, ihre volle Berechtigung.

61 So auch Rosati ${ }^{2} 2013$, ad met. VI, 415.

$62 \mathrm{Zu}$ den Details s. Cole 2004, $387 \mathrm{f}$. 
Pelops-Pittheus der Auftritt des in den folgenden zwei „Metamorphosen“-Büchern maßgeblich wirkenden Theseus vorbereitet und die nur über Pelopeiades Mycenae implizierte, aber viel prominentere Linie Pelops-Atreus-Agamemnon zurückgedrängt wird, welche erst ab dem zwölften Buch in den Vordergrund rückt und in den dazwischenliegenden Büchern in beredtem Schweigen übergangen wird. ${ }^{63}$ Als genealogischer Fingerzeig sozusagen lenkt die Erwähnung von Pittheus, Theseus’ Großvater, Erzieher und - in der erzählten Welt selbst offenbar - baldiger Herrscher von Troizen, das Augenmerk auf den in den nächsten Büchern relevanteren Teil des Pelopsgeschlechts zu Ungunsten des anderen. ${ }^{64}$

Entlang den beiden mit nondum und neque adhuc gekennzeichneten Fixpunkten kommen dann die weiteren Zeitaspekte zum Tragen, die der leserseitigen Erwartung einer verlässlichen zeitlichen Strukturierung der Erzählung jedoch entschieden widerstreben. Angedeutet schon durch die rahmende Aktualisierung, dass Städte ihre Könige um eine Trauergesandtschaft baten (413), ein officium, wie später (422) ergänzt wird, geben die dargebotenen Städte, die katalogartig teils ohne, teils mit unscheinbaren oder mit teils für die Zeit der Handlung kontradiktorischen Eigenschaften beschrieben werden, keine verlässlichen Anhaltspunkte über den gegenwärtigen Zustand. Das Entscheidende ist aber, dass sie den Anschein erwecken, es zu tun. Denn die in der adjektivischen Attribution liegende Implikation einer Gleichzeitigkeit zwischen Attribut und Nomen wird nicht in ihrer Gültigkeit eingeschränkt, wodurch es nicht zuletzt wegen der sonstigen Erzählweise in der gesamten Passage naheliegt, sie als eine Beschreibung der diegetischen Gegenwart anzusehen.

Neben der auf plausiblen Angaben fußenden Überleitung wird dadurch ein zweiter, wohl gleichwertiger Effekt sichtbar, der den Status der Erzählung auf einer extradiegetischen Ebene problematisiert, die nichts mit dem Handlungskontext selbst zu tun hat. In den poetischen Synchronismen macht sich die Präsenz des Erzählers bzw., um dies in Bömers Worte zu fassen, der persona poetae nachdrücklich bemerkbar, ohne dass dies von seiner formalen Darbietung her als signifikant anders gegenüber den vermeintlich richtigen übrigen Informationen klargemacht ist. Der grundsätzliche, aber konventionell als nicht vorhanden kaschierte Unterschied zwischen der epistemischen Privilegierung der Erzählerstimme und der ihr logisch untergeordneten erzählten Welt bleibt hier nicht nur nicht verborgen, sondern wird in einer quasi-historischen Situation ${ }^{65}$ anhand des sich formal bei den Epitheta traditionsgemäß bietenden Potenzials bewusst evoziert. Folglich ist auch die von jener

63 Vgl. ebd., 393f. Weder Atreus und Thyest noch Agamemnon und Menelaos werden in den Büchern sieben bis elf in irgendeiner Form direkt erwähnt.

$64 \mathrm{Zu}$ einem ähnlichen Schluss hinsichtlich der Genealogie insgesamt kommt auch Tronchet 1998, $336 \mathrm{f}$.

65 Man beachte in diesem Kontext auch die Perfektformen oravere (413), cessastis (421) und obstitit (422), die sich auf die Gesandtschaft selbst beziehen und durch ihr Tempus von den anderen Hauptverben coeunt (412) und terrebant (423), die anderes oder hintergründiges Geschehen abbilden, abgesetzt sind. 
Konvention suggerierte Objektivität, die vor allem für faktuale oder sich faktual gebende Texte eine Grundvoraussetzung ist, für die von einer solchen Stimme auf diese, d. h. lediglich implizite Weise getätigten Aussagen aufgehoben. Als historisches Medium und sicherer Gewährsmann für die dargestellten Ereignisse disqualifiziert sich ein solcher Erzähler zwangsläufig.

Und Ovid wäre nicht Ovid, wenn nicht auch dieser Aspekt, die Unglaubwürdigkeit bzw. die Künstlichkeit des Dargestellten, expressis verbis zur Sprache gebracht wäre, was selbst wiederum in nicht nur einer Hinsicht verstanden werden kann. Denn die rhetorische Frage credere quis posset (420), die angesichts des Fernbleibens der so wichtigen Stadt Athen eine natürliche Reaktion zu sein scheint, ${ }^{66}$ dürfte vielmehr als „Zusatz ex persona poetae“ ${ }^{67}$ die Distanz des Sprechers von den berichteten Vorgängen unterstreichen und damit die Überleitung und den mit ihr verfolgten Zweck kommentieren. ${ }^{68}$

Die Stellung am Ende des Katalogs, durch die das Nennen des für den ganzen Passus entscheidenden Details - Athen ist aus einem ganz bestimmten Grund verhindert - retardierend vorbereitet wird, setzt die nachfolgenden zweieinhalb Verse deutlich vom Vorherigen ab und stellt sowohl deren Besonderheit als auch die sie berichtende Erzählsituation heraus: Der Unglaube des Erzählers ist scheinbar so groß, dass er sich veranlasst sieht, seine Worte in Form einer diskursiven Metalepse direkt an die Stadt zu richten (solae cessastis Athenae - 421) und das adressierte Objekt, dessen Abhängigkeit vom Sprecher auf diese Weise explizit zur Geltung kommt, in seinen Gedankenhorizont miteinzubeziehen. ${ }^{69}$ So ist zum einen der wesentliche letzte Aspekt des Katalogs effektvoll in Szene gesetzt, der das notwendige Verbindungsglied zum danach darzustellenden, neu beginnenden Themenkomplex bildet; zum anderen fordert die offensive Zurschaustellung des eigenen Erzählerstandpunkts zusammen mit der Anzweiflung des Wahrheitsgehalts dessen, was von eben jenem Standpunkt erzählt wird, dazu auf, den Vers als Rückverweis auf das eigene Erzählen und dessen Gemacht-Sein zu lesen.

Dafür spielt es auch eine Rolle, dass Ovid diese Überleitung in nahezu identischer Weise im ersten Buch bei Peneios schon einmal verwendet hat: der Auslöser ein Traueranlass, danach ein Katalog an Kondolierenden, dann die einzige Ausnahme, hier eine Stadt, die aus einem guten, weil dann noch zu beleuchtenden Grund nicht da sein kann. ${ }^{70}$ Statt diesen Textbaustein also schlicht unterschiedslos zu wiederholen,

66 Vgl. Rosati ${ }^{2} 2013$, ad met. VI, 421-423.

67 Bömer ${ }^{2} 2008$, ad loc.

68 Vgl. Anderson 1972, ad loc.

69 Diese Metalepse bezeichnet Bömer ${ }^{2} 2008$, ad loc., als „Anrede ex persona poetae“, sodass deutlich wird, dass neben dem bereits zitierten „Zusatz ex persona poetae“ im ersten Halbvers auch in der anderen Hälfte die persona poetae durch die „Anrede“ vertreten ist und der Vers gänzlich von dieser Perspektive geprägt ist.

70 Bei Peneios sind sich die Flüsse allerdings nicht sicher, ob sie ihn für die Metamorphose seiner Tochter beglückwünschen oder betrauern sollen (nescia, gratentur consolenturne parentem - met. I, 
wird er hier am Anfang der zweiten Pentade wiederaufgegriffen. Dabei ist er sowohl in seiner thematischen Spannung gesteigert, indem die eben im Detail beobachteten zeitlichen Ver- und Verunsicherungen das gesamte Bedeutungsspektrum zwischen verlässlichen und unverlässlichen Informationen ausschöpfen, als auch witzig pointiert in Bezug gesetzt zur früheren Stelle: Nach Beendigung des Katalogs wird das Fehlen Athens mit einer affektiert wirkenden Bemerkung im Sinn von „Na, wer hätte das wohl gedacht?“ eingeleitet. Der Erzähler ironisiert sich selbst, indem er auf den Synchronismus im ersten Buch zurückverweist.

Die tatsächliche Ursache für die Abwesenheit Athens - die Belagerung durch ein feindliches Heer ${ }^{71}$ stellt nicht nur einen wohl bestmöglichen, daher vielleicht sogar $z u$ guten Grund dar, sondern auch die Ursache selbst, die der Schlusspunkt der synchronistischen Überleitung ist, wird in formvollendeter, geradezu perfekter Gestalt vorgetragen (Vers 423):

barbara Mopsopios terrebant agmina muros.

Ohne die metrisch-syntaktische Besonderheit überbewerten $\mathrm{zu}$ wollen, ist es kein Zufall, dass gerade hier auch noch eine „golden line“ bzw. ein versus aureus, nach dem Muster Adjektiv a/Adjektiv b/Verb/Nomen A/Nomen B (abVAB), steht. ${ }^{72}$ Aufgrund seiner Symmetrie und perfekten Aufteilung bei den einzelnen Satzgliedern mitsamt zugehörigen Attributen scheint dieser Hexameter als zu gut und deswegen künstlich empfunden worden zu sein und, in Anbetracht seiner statistischen Auftretenshäufigkeit in lateinischer Dichtung, eher dem neoterischen Stilideal entsprochen zu haben als dem hohen Stil des Epos. ${ }^{73}$ Die betont artifizielle Form korrespondiert demnach äußerst gut mit der gesucht wirkenden und offenbar gerade deswegen ostentativ vorgeführten inhaltlichen Motivik, sodass der intratextuelle Bezug auf die frühere Stelle und andere Übergangstechniken und die metapoetisch-ironische Kritik am eigenen Dichten erkennbar wird. ${ }^{74}$

Der Gesamteindruck, der sich in dieser Passage bietet, könnte daher am besten als ein Weder-Noch aus verschiedenen Diskursen zusammengefasst werden: dem grundlegenden diegetischen zum einen, der das logische Verbindungsstück zwischen zwei Handlungssträngen darstellt und die Kontinuität der Erzählung bezweckt, welche über die sozusagen verlässlichen Wegmarken Pelops, Kalydon, Troizen, Pandion

578). Beispiele für ähnliche Überleitungen mit dem Motiv „alle, nur einer nicht“, aber ohne Katalog und nicht immer in Verbindung mit dem Trauermotiv finden sich bei Bömer ${ }^{2} 2016$, 287 und Bömer ${ }^{2} 2008$, ad met. VI, 162.

71 Das kann im Lichte der nur spärlich verfügbaren Quellen als Erfindung Ovids gewertet werden. Vgl. ebd., ad met. VI, 423 und Anderson 1972, ad met. VI, 421- 423.

72 Der Hinweis darauf findet sich bei ebd., ad loc.

73 Vgl. Norden ${ }^{3} 1926,393-395$ und die Tabellen bei Mayer 2002, 161.

74 Die Ähnlichkeit zu den Anachronismen ist augenscheinlich. S. o. Kap. 5.1. 
in der Tat auch etabliert wird, ${ }^{75}$ und dem extradiegetischen Diskurs zum anderen, in dem eine textnahe Interaktion mit und Gegentendenz $z u$ der grundlegenden zeitlichen Stabilisierung stattfindet. Mittels poetischer Syn- und Anachronismen erweist sich der Standardmodus epischen Erzählens, der in seiner Katalogform und anhand weiterer Eigenheiten prätentiös normal und objektiv wirken möchte, als durch und durch subjektiv und nicht-historisch. An diese Desillusionierung durch die spürbare Erzählerpräsenz anknüpfend tritt zuletzt noch die Reflexion des eigenen Erzählens in Erscheinung, indem ein strukturgleicher Textbaustein wiederaufgegriffen und in witziger Weise als offensichtlich unglaubwürdig ausgewiesen wird. ${ }^{76}$

Wie aber keiner der eben genannten Diskurse oder Aspekte isoliert für sich zur Geltung kommt, ${ }^{77}$ so ist der ästhetisch-intellektuelle Reiz dieser Passage einzig aus einer Zusammenschau erfahrbar, in der ihre Tendenzen sowohl an und für sich als auch in ihrer gegenseitigen Bedingtheit und Kontradiktion als gleichwertig und -zeitig Berücksichtigung finden. ${ }^{78}$ An einer Stelle, an der „kein chronologischer Schnitt, kein Schritt in die Geschichte hinein, sondern thematisch-atmosphärischer Wandel ${ }^{\text {“79 }}$ verhandelt wird, ist dies genau an seinem Platz.

\subsection{Ein Fest ohne Gründer - der Panathenäen-Festzug in met. II, $708-713$}

Nun gleichfalls selbst von diesem Beispiel aus dem sechsten Buch zum nächsten im zweiten überzuleiten, fällt insofern nicht schwer, als einerseits die voranstehenden Schlussfolgerungen ohne Abstriche auch hier gelten und andererseits mit Athen der Schauplatz derselbe ist. ${ }^{80}$ Diesem nähert sich der Erzähler im zweiten Buch zum ersten Mal, nachdem er zuvor noch im Westen der Peloponnes die Geschichte vom Hirten Battos erzählt hat, der die Rinder und Pferde von Nestors Vater Neleus hütet

75 Hinweise zu weiteren intratextuellen Bezugnahmen finden sich im Kommentar zu dieser Passage von Rosati ${ }^{2} 2013$.

76 Was vergleichbar ist damit, dass im ersten Buch der „Metamorphosen“ Merkur auf eine Geschichte zum Einschläfern zurückgreift, wie sie Ovid kurz vorher - passenderweise mit dem Peneios-InachosSynchronismus verbunden - in verblüffend ähnlicher Gestalt über Apollon und Daphne selbst erzählt hat. S. dazu Barchiesi ${ }^{4} 2013$, ad met. I, 689-712.

77 Der diegetische wäre für sich betrachtet nur ein langweiliger Bericht, der extradiegetisch-desillusionierende ein zusammenhangloses zeitliches Wirrwarr und der extradiegetisch-metapoetische ein manieriertes Spiel.

78 Zum Gedanken s. Feldherr 2002, $177 \mathrm{f}$.

79 Schmidt 1991, 125.

80 Außerdem erwähnenswert ist, dass der in Minervas Kunstwerk dargestellte Wettstreit mit Poseidon um die Schirmherrschaft der Stadt (met. VI, 70 - 82) als Analepse nachträglich erklärt, warum Attika im zweiten Buch gratamque Minervae ... humum (,das Land, das der Minerva willkommen ist ${ }^{\text {‘ }}$ - met. II, 709f.) genannt wird. 
und für seinen Treuebruch in einen Stein verwandelt wird. ${ }^{81}$ Folgendermaßen wird dies dargestellt:

\author{
Hinc se sustulerat paribus Caducifer alis \\ Munychiosque volans agros gratamque Minervae \\ despectabat humum cultique arbusta Lycei. \\ illa forte die castae de more puellae \\ vertice supposito festas in Pallados arces \\ pura coronatis portabant sacra canistris. ${ }^{82}$
}

Bemerkenswert ist zunächst, dass das Geschehen von Merkurs Blickwinkel aus, der im Flug auf die Landschaft hinabsieht (despectabat - 710), geschildert ist. ${ }^{83}$ Mit diesem Blick aus den Augen seiner Figur impliziert Ovid erneut, dass alles, was diese in ihrer Welt wahrnimmt, dort auch vorhanden sein muss. ${ }^{84}$

So ist man bei den cultique arbusta Lycei (710) dazu angehalten, sich die Baumpflanzung im Nordosten der athenischen Akropolis als existent vorzustellen, die dem Apollon Lykeios geweiht, aber in der Antike besonders für das dort befindliche Gymnasion und dessen Wandelhalle, den Peripatos, bekannt war, wo die von Aristoteles begründete Philosophenschule ihren Sitz hatte. ${ }^{85}$ Als Aktualisierung,

81 Da eine textnahe Besprechung dieser Stelle bereits andernorts erschienen ist (vgl. Geitner 2019), werden in diesem Kapitel nur die wesentlichen Aspekte noch einmal herausgearbeitet und begrifflich präzisiert, was im Artikel nicht erfolgt ist, da dort nur von Anachronismen bzw., anlässlich des betreffenden Tagungstitels, Zeitmontagen die Rede ist.

82 Met. II, 708-713: ,Von dort hatte sich der Stabträger mit dem Flügelpaar aufgeschwungen und blickte im Flug hinunter auf das Gebiet um Munychia, auf das Land, das der Minerva willkommen ist, und auf den Hain des kultivierten Lykeions. Es traf sich, dass an jenem Tag züchtige Mädchen, wie es der Sitte entsprach, zur festlich gestimmten Burg der Pallas reine Opfergaben trugen, in umkränzten Körben gestützt auf ihren Köpfen.

83 Zum Flug als narrativem Konnektor in der fiktiven Welt s. Tronchet 1998, 286.

$84 \mathrm{Vgl}$. Fondermann 2008, 83. Ähnlich wie oben bei den Epitheta nutzt Ovid damit auch hier einen semantischen Spielraum aus, der sich durch eine sprachlogische Beziehung in einem fiktionalen Narrativ eröffnet - in diesem Fall den einer Präsupposition: Wenn die Aussage getätigt wird, dass jemand ein konkretes Objekt sieht, dann ist darin zwangsläufig vorausgesetzt, dass dieses Objekt auch existiert. Eine solche Voraussetzung wird als Präsupposition und ein Verb wie „sehen“ als Präsuppositionsauslöser bezeichnet. Vgl. Ernst 2002, 31-38. Indem nun Ovid als extradiegetischer Erzähler diese Aussage tätigt, impliziert er für die erzählte Welt die Gültigkeit dieser Aussage mitsamt der durch sie ausgedrückten Präsupposition. Interessant ist die Tabelle für die Häufigkeit von Wörter des visuellen Wahrnehmens bei Ovid im Vergleich zu Vorgängern und Nachfolgern bei Fondermann 2008, 121.

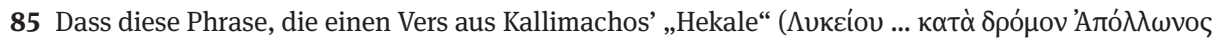
- ,entlang bzw. an der Rennbahn des Apollon Lykeios‘ - Kall. Hek. Fr. 71, 2-3 Hollis) mitsamt der dort schon vorhandenen Aktualisierung aufgreift, dieses Lykeion meint, legt sowohl die Flugrichtung Merkurs von Südwest nach Nordost nahe als auch das Adjektiv culti, wodurch gerade der kulturelle Aspekt dieser Lokalität betont wird. Vgl. dazu den Hinweis bei Bömer 2006, ad met. II, 708f. und Solodow 1988, 79. Dabei kann der Genitiv Lycei sowohl den Beinamen von Apollo Lyc(a)eus meinen oder das neutrale Lyceum selbst (OLD kennt anders als der Georges das Adjektiv Lyceus als Abwandlung von Lycaeus nicht), sodass vordergründig eine in den Grenzen der Diegese unproblemati- 
die der Sicht des Erzählers und nicht der des diegetischen Personals entspringt, ist die Aussage sowohl an sich schon bedeutsam, aber hier mit dem entscheidenden Extra, dass sie über den Kopf hinweg von derjenigen Figur geschieht, die sie eigentlich beobachtet. ${ }^{86}$

Dass der Betrachtungsgegenstand mit illa forte die (711) als ein zufälliges Ereignis eingeleitet wird, lässt wiederum an einer entscheidenden Stelle die Erzählerironie aufblitzen: ${ }^{87}$ Merkur sieht in der Stadt einen Festzug, eine Pompe, in der es Brauch (de more) zu sein scheint, dass jungfräuliche Mädchen (castae puellae) reine Opfergaben (pura sacra) auf die der Athene geweihte Akropolis (festas in Pallados arces) in geschmückten Körben (coronatis canistris) auf ihren Köpfen (vertice supposito) tragen. Die Vielzahl an charakteristischen Details - von denen insbesondere die sog. Kanephoren, die korbtragenden Jungfrauen, als die erwählt zu werden im Athen der klassischen Zeit eine hohe Auszeichnung war, ${ }^{88}$ sowie die Destination Akropolis zu nennen sind - weisen das Ereignis als Panathenäen-Festzug aus. ${ }^{89}$

Der Verweis auf eine Tradition mittels de more (712), das sowohl auf die castae puellae, wovon es umrahmt wird, als auch auf das Prädikat portabant bezogen werden kann, ist darüber hinaus noch auffällig, als es in beiden Fällen die jeweilige Aussage hinsichtlich einer zeitlichen Dimension modifiziert: Denn wo eine Tradition ist und dementsprechend eine Handlung als de bzw. contra morem beurteilt werden kann, muss zuvor eine spezifische historische Entwicklung stattgefunden haben, die genau diesen mos hervorgebracht hat. ${ }^{90}$ Dieser Zusatz impliziert daher - auch durch Anschaulichkeit und ein späteres intern-fokalisiertes Wiederaufgegriffen unterstri-

sche und wohl auch vorzuziehende Lesart ermöglicht ist, während zugleich gegen die sehr deutliche Assoziation mit dem Lyceum nicht einmal grammatikalisch etwas eingewendet werden kann. Das Gymnasium als Sportstätte, wie es noch bei Kallimachos durchscheint, kommt im ovidischen Ausdruck nicht mehr eigens zur Geltung. Die von Zissos/Gildenhard 2004, 64 (Anm. 65) gewählte Bezeichnung als „sportive anachronism“ ist deshalb unpassend.

Der in der Tradition früheste Stifter des Hains ist der Pandionide Lykos, der aber von der diegetischen Gegenwart aus betrachtet auch erst mehrere Generationen später leben würde. Vgl. Kruse 1927, 2268f.; als Gründer des dort befindlichen Gymnasion, in dem Aristoteles seine Schule dann hatte, sind entweder Peisistratos, Perikles oder ein Lykurgos überliefert. Vgl. Kroll 1927, $2267 \mathrm{f}$.

86 S. o. Kap. 5.2. Für die Vermutung, dass auch die Nennung von Munychia eine merkmalhafte Aktualisierung ist, auch wenn es an dieser Stelle ein unspezifisches Toponym zu sein scheint, s. Geitner 2019, 124 f. und 132-134. Vgl. auch Anderson 1972, ad 708-710: „Ovid picks out two parts of the city that would be familiar to many of his Roman audience who visited the city [...]. No doubt, the audience would enjoy the obvious unmythical anachronism.“

87 Für weitere Hintergründe hierzu s. Geitner 2019, 135.

88 Dieser Aspekt könnte auch leise dabei anklingen, dass Herse wenige Zeilen später als decus pompae comitumque suarum (Zierde des Festzugs und ihrer Begleiterinnen' - 725) bezeichnet wird. 89 Vgl. Bömer 1969, ad met. II, 713.

90 Durch de more wird daher auch der Erzählerstandpunkt deutlicher erkennbar, der für die Beschreibung des Festzuges zudem von der internen zur Nullfokalisierung gewechselt ist. 
chen $-{ }^{91}$ dass es sich um einen historisch gewachsenen und authentisch wiedergegebenen Zustand handelt. Nach den bisherigen Beobachtungen zu urteilen, ist eine Schilderung des Panathenäen-Zuges während der Regentschaft des Kekrops ${ }^{92}$ aber noch kein Fall für einen poetischen Synchronismus.

Ein solches Detail ist allerdings durchaus vorhanden und wird mehrfach in Erinnerung gerufen: Erichthonios, neben dem noch viel späteren Theseus der mythische Gründer der Panathenäen, ${ }^{93}$ ist durch eine andere Geschichte, die im Kontext des im zweiten Buch verhandelten Schwätzer-Motivs erzählt wird, schon zuvor in ein direktes Verhältnis zu den Kekropstöchtern gesetzt. Der Zusammenhang ist folgender:

nam tempore quodam

Pallas Ericthonium, prolem sine matre creatam, clauserat Actaeo texta de vimine cista virginibusque tribus gemino de Cecrope natis et legem dederat, sua ne secreta viderent. ${ }^{94}$

Zwar ist die Zeitangabe mit tempore quodam (552) durchaus vage, ${ }^{95}$ aus der Handlung geht aber hervor, dass Erichthonios ein Baby ist und die Kekropiden mindestens in einem Alter sind, in dem sie einerseits als virginibus $(555)^{96}$ bezeichnet werden können und andererseits von Athene schon für so vernunftbegabt gehalten werden, dass sie sie mit der Aufsicht über die Kiste betraut. ${ }^{97}$ Wenn von Merkur folglich wenige hundert Verse später erzählt wird, dass er über die Stadt fliegt und sich beim Anblicks Herses, einer der drei die Panathenäen feiernden Töchter des Kekrops, Hals über Kopf in sie verliebt, kann zwischen den Vorgängen in der Episode

91 So nähert sich später (met. II, 794-796) Invidia, der personifizierte Neid, der Stadt und muss in all ihrer Missgunst feststellen, dass es nichts Beweinenswertes darin zu sehen gibt, weil sie sowohl in geistiger und politischer Blüte (ingeniis opibusque - 795) als auch in festlichem Frieden (festa pace 795) steht. S. dazu Geitner 2019, 132-134.

92 Diese lässt sich indirekt dadurch bestimmen, dass dessen Töchter, explizit natae Cecropis genannt (met. II, 555 und 784), am Zug teilnehmen.

93 Vgl. Parker 2000, 230.

94 Met. II, 552-556: ,Denn einstmals hatte Pallas den Erichthonios, den ohne Mutter erzeugten Spross, in einen Korb eingeschlossen, geflochten aus attischer Weide, und den drei von Kekrops abstammenden Jungfrauen mit dem Gebot übergeben, dass sie ihr Geheimnis nicht ansähen.

$95 \mathrm{Ob}$ damit das Ereignis weit in die Vergangenheit zurückgelegt wird, wie Barchiesi ${ }^{4} 2013$, ad met. II, 748, anmerkt, ist zu bezweifeln, weil tempore quodam nicht viel mehr als ,irgendwann einmal bedeutet und jeweils davon abhängt, in welchen Zeitdimensionen ein Sprecher, hier wohlgemerkt eine Krähe, grundsätzlich denkt, ob also in Tagen, Jahren oder Jahrzehnten.

96 Damit ist typischerweise ein mit Jugend assoziierter Zustand zwischen Kindheit und einem Dasein als verheiratete Frau gemeint. Weil aber die Kekropiden in met. II, 555 als virginibus bezeichnet werden, widerspricht es schon allein den Angaben des Textes, wenn ein Reifeprozess zu einer virgo bis zur späteren Stelle, wo von puellae (met. II, 711) die Rede ist, behauptet wird (so bei Cole 2004, 380). 97 Zum Kindheitsmotiv in den „Metamorphosen“ s. auch die demnächst erscheinende Arbeit von Julia Worlitzsch. 
mit der Kiste und dem Zeitpunkt des Festzuges nicht viel Zeit verstrichen sein. Dies bekräftigt die Erzählung sowohl implizit, weil Herse nach dem gängigen Schönheitsideal wohl für Merkur nur als Jugendliche virginibus praestantior omnibus gewesen sein dürfte; ${ }^{98}$ als auch sogar explizit durch eine zeitliche Markierung des Erzählers. Denn über jenen Wortbruch bzw. über die Augen, die das Verbotene betrachtet haben, heißt in Bezug auf Herses Schwester Aglauros:

aspicit hunc oculis isdem quibus abdita nuper

viderat Aglauros flavae secreta Minervae. ${ }^{99}$

Dieses als ,neulich' bezeichnete und wiederum durch eine interne Fokalisierung aus der Sicht der Aglauros mitgeteilte Ereignis erhält dann sogar noch seine Verifizierung durch die Gegenperspektive Athenes, die ebenso intern fokalisiert berichtet wird. Weil Aglauros Merkur gegenüber dreist auftritt, erinnert sich die Göttin - und erinnert den Leser passenderweise gleich mit -, dass die Schwestern ja wortbrüchig waren und gegen sie gefrevelt haben: ${ }^{100}$

subit hanc arcana profana

detexisse manu, tum cum sine matre creatam

Lemnicolae stirpem contra data foedera vidit. ${ }^{101}$

Die lexikalischen Überschneidungen zwischen den drei Passagen sind daher ebenso evident wie die in ihnen handelnden Akteure, besonders Erichthonios, der im ersten Beispiel namentlich und über sein markantes Charakteristikum identifizierbar ist sowie im letzten unter Wiederholung des sine matre creatam mit Ergänzung seiner Abstammung väterlicherseits ausgewiesen wird. Damit ist die frühere Episode, in der Erichthonios ein Baby ist und in die Obhut der Kekropiden gegeben wird, und das gegenwärtige Geschehen um Merkurs Liebesabenteuer mit Herse, die er bei dem Festzug erblickt, eng und auch in zeitlicher Hinsicht miteinander verknüpft: ${ }^{102}$ Das Panathenäen-Fest einerseits und sein eigentlicher Gründer andererseits werden in

98 Met. II, 724: ,unter allen Jungfrauen herausragend‘.

99 Met. II, 748 f.: ,Diesen [sc. Merkur] blickt Aglauros mit denselben Augen an, mit denen sie neulich das verhüllte Geheimnis der blonden Minerva angeblickt hatte.

100 S. zur internen Fokalisierung auch die Erläuterung bei Barchiesi ${ }^{4} 2013$, ad met. II, 748 -752, wonach damit ein für die nachfolgende Invidia-Handlung wichtiger perspektivischer Aspekt vorbereitet wird.

101 Met. II, 755 - 757: ,Da kam ihr wieder in den Sinn, dass diese damals doch mit entweihender Hand das Geheimnis offengelegt hatte, als sie gegen die getroffene Abmachung den ohne Mutter erzeugten Spross des auf Lemnos beheimateten Gottes betrachtet hatte.'

102 Nicht überzeugend ist daher die historistische Deutung bei Cole 2008, 33f. Ungeachtet hiervon ist eine Betonung eines wirklichen Zeitunterschieds von nuper (748) in der Fokalisierung von Aglauros und dem tum cum (756) bei Athene wenig stichhaltig, weil das cum selbst eine zeitliche Beziehung ,neulich“ nicht ausschließt und aus der Sicht einer Göttin ein solches Ereignis sehr plausibel als eines von vielen anderen beurteilt werden kann, die ein Gott in seinem „Alltagsgeschäft“ zu bewältigen hat. 
der diegetischen Gegenwart auf widersprüchliche Weise als gleichzeitig behauptet. Erkenntnisreich ist dabei, wie und mit welchem Nachdruck die hierfür relevanten Aussagen zum Ausdruck gebracht werden. Denn augenfällig genug dürfte es sein, dass weder Erichthonios als Kultstifter oder als König vorgestellt wird, sondern als nebensächlicher Aspekt in einer sich zwischen Athene und den Kekropstöchtern abspielenden Vorgeschichte zum Vorschein kommt; ${ }^{103}$ noch auch die Panathenäen mehr als die sehr anschauliche Szenerie dafür bieten, dass Herse von Merkur gesehen wird und sich das Liebesabenteuer abspielen kann. ${ }^{104}$ Synchronistisch sind folglich nicht genannte Merkmale bei für die Diegese hintergründigen Phänomenen, die sich ergeben entweder aus der Implikation einer namentlichen Nennung wie im Falle des Erichthonios oder wie bei den Panathenäen einer Beschreibung, die auf einige sehr typische Charakteristika des zu imaginierenden Vorgangs zurückgreift. Beide Informationen sind in keiner Weise expliziert und werden darüber hinaus ebenso wenig direkt auf das andere zeitlich widersprüchliche Objekt bezogen. ${ }^{105}$

Gerade bei Erichthonios hat es den Anschein, dass seine Rolle an den Geschehnissen, während die Erzählung des zweiten Buches in Athen weilt, auf ein Minimum zurückgedrängt ist: Seine eigentliche Geschichte mit den Kekropiden ist sozusagen hypodiegetisch ausgelagert, mit tempore quodam (552) in ein zeitliches Niemandsland gesetzt und in ein aitiologisches Narrativ eingebettet, welches eine Krähe als Mahnung gegenüber einem Raben ausspricht. ${ }^{106}$ Erichthonios selbst oder die mit ihm verbundene Mythhistorie wird aber nicht behandelt. Gleiches ist der Fall

103 Einen weiteren Auftritt, erneut nur als nebensächliches Objekt der eigentlichen Handlung und als ein Beispiel von vielen, hat Erichthonios dann nur noch, als sein oben Lemnicola (757) genannter Vater Vulcanus auch für seinen Schützling ein zweites Leben fordert (met. IX, 423f.).

104 Laut einem Homer-Scholion liegt das Motiv, dass eine Königstochter als Kanephore von einem Gott beachtet bzw. geraubt wird, auch bei Orithyia vor, die, wie auch Ovid in met. VI, $702-710$ (ohne dieses Detail zu erwähnen) schildert, das Opfer des Windgottes Boreas wird. Vgl. Mittelhaus 1919, 1865.

Die Panathenäen als Beweis dafür zu lesen, dass Kekrops nicht mehr an der Macht ist (so Cole 2004, 380), lässt abgesehen davon, dass er als ein zu fürchtender Vater für das diegetische Geschehen noch bedeutsam ist (so in met. II, 813), vor allen Dingen unberücksichtigt, dass eine Aktualisierung als uneigentliches Sprechen per se keinen in einer diegetischen Umgebung als historisch zu bezeichnenden Zustand beschreiben kann (s.u. Kap. 7.1). Gleiches gilt für die ohnehin äußerst verkürzte und einseitige Auslegung von Munychios agros und culti arbusta Lycei (met. II, 709f.) bei Cole 2008, 93, als Beweis für die Existenz von „cultivated fields and gardens“ (!). Objekten, die Ovid mit an Sicherheit grenzender Wahrscheinlichkeit nicht im Wortsinn so nennt (Munychia ist bezeichnenderweise ein 86 m hoher Hügel am Meer; vgl. Kruse 1933, 565 und Bömer 1969, ad met. II, 709) und die nicht nur der internen Fokalisierung durch einen fliegenden Gott entstammen, sondern in einer gänzlich aktualisierten, d. h. aus der zeitlich antizipierenden Perspektive eines extradiegetischen Erzählers geschilderten Szenerie stehen, einen faktischen Status zuzuschreiben, ist geradezu absurd. Ganz zu schweigen davon, just darin einen sich bietenden Kontrast zu einem fünf Bücher später stehenden Katalog zu sehen (so Cole 2008, 93 (Anm. 189)).

105 Aus diesem Grund auch ist die von Bömer gegebene Bemerkung, dass „über solche chronologischen Fragen der Dichter sich den Kopf nicht zerbrochen“ (Bömer 1969, ad met. II, 713) habe, ungenügend bzw. bestenfalls missverständlich.

106 Vgl. Zissos/Gildenhard 2004, 55. 
beim zweimaligen Wiederaufgreifen des Krähen-Berichts im Kontext von Merkurs Affäre: Auch da dient dieser der erzählerischen Motivierung der Handlung - die neugierigen Augen der Aglauros, das Gefühl der Kränkung bei Athene -, ohne dass auch nur eine einzige neue Information über Erichthonios gegeben wird. ${ }^{107}$ An ein Dasein als König oder als sonst handlungsrelevanter Akteur in der diegetischen Gegenwart zu denken, dazu fordert der Text demnach bei einer Figur, die nur als Baby in einer Kiste Erwähnung findet, kaum auf.

Im Gegenzug verfügt die Feierlichkeit scheinbar in spiegelbildlicher Weise über eine sehr präzise Charakterisierung, jedoch nicht über eine eindeutige Benennung. Indem bei dem als Panathenäen zu identifizierenden Fest dann sogar noch auf eine Tradition verwiesen wird, scheint jeder Zweifel an deren Existenz in der fiktiven Welt, in der auch Munychia und das Lykeion zum Stadtbild gehören, unangebracht. ${ }^{108}$ Was einerseits das fiktive Objekt „Panathenäen“ an semiotischer Eindeutigkeit, d. h. namentlicher Determination entbehrt, ist durch ein sehr dichtes und markantes Aufbieten seiner kennzeichnenden Eigenschaften ersetzt; das fiktive Objekt „Erichthonios“ andererseits ist durch seinen Namen oder durch auf diesen rekurrierende Umschreibungen klar determiniert, weitere möglicherweise wichtigen Charakteristika - vor allem, dass er der Gründer jenes Festes ist - fehlen aber und ein direktes In-Beziehung-Setzen dieser nicht genannten Eigenschaften zum diegetischen Geschehen, wozu die namentliche Nennung trotzdem auffordert, wird zusätzlich durch eine Erzählung erschwert, die dessen Stellung marginalisiert.

Der poetische Synchronismus bei den Panathenäen und Erichthonios steht somit genau in einem Grau- oder Überschneidungsbereich, der sich entlang semantischer Leerstellen und der aktualisierenden Perspektive des Erzählers eröffnet, die überdies in seiner fiktiven Realität durch die Augen Merkurs und Invidias multiperspektivisch verifiziert wird. In den Grenzen der Diegese wird dadurch eine Möglichkeit der Interaktion der beiden Objekte hinsichtlich derjenigen logischen, d. h. auch zeitlichen Beziehung abgeschwächt, wie sie ihnen eigentlich zukommt, während die bestehenden Implikationen, die deren Nennung oder Schilderung zwangsläufig nach sich ziehen, von Seiten des Erzählers nicht kommentiert werden und deshalb gültig bleiben.

107 Für das Verständnis der Stelle met. II, 748f. sind die Informationen der vorherigen Passage met. II, 552-556 sogar eine wichtige Voraussetzung, wohingegen met. II, 755-757 wie ein leicht abgewandeltes Zitat der Krähen-Erzählung wirkt: zweimaliges sine matre creatam (553 und 756), videre (556 und 757) sowie ähnliche Formulierungen bei prolem (553) gegenüber stirpem (757), legem dederat (556) gegenüber data foedera (757), s. dazu auch Bömer 1969, ad met. II, 757, und secreta (556) gegenüber arcana (755).

108 Nennenswert ist in diesem Kontext auch die Bemerkung Bömers zu einer anderen historistischen, d. h. den Text als Zeugnis für ein historisches Ereignis heranziehenden Schlussfolgerung. Im RE-Artikel zu den „Kanephoroi“ (vgl. Mittelhaus 1919, 1865) wird unter alleiniger Berufung auf die „Metamorphosen“-Stelle, wohlgemerkt aus einer fiktionalen Erzählung eines lateinischen Autors zur Zeit des Augustus heraus, die Zugehörigkeit des Hermes zum Panathenäen-Kult als „,reale Kulttatsache“ (Bömer 1969, ad met. II, 713) hingestellt und ist auch in den Augen Bömers kritikwürdig. 
Wie schon bei den Epitheta ornantia erweckt an dieser Stelle gleichfalls die Art, wie der extradiegetische Erzähler die diegetische Handlung darbietet, den Eindruck von epischer Objektivität in einem Moment höchster erzählerischer Subjektivität. Darum ist auch hier, um noch einmal Herders Einschätzung zu wiederholen, „weder eine Urwelt noch eine gebildete “109 darzubieten beabsichtigt: Wie in einer Art Schwebezustand stehen sich nämlich Aussagen mit kontradiktorischen Zeitimplikationen gegenüber und sollen offenbar simultan Gültigkeit für sich beanspruchen.

Das vordergründige Geschehen - die Affäre von Merkur mit Herse und die Missgunst ihrer Schwester Aglauros, deren Verwandlung in einen Stein die Episode beschließt - wird durch das aktualisierende, extradiegetisch-unzeitgemäße Kolorit sehr lebendig in Szene gesetzt, was ihm nicht zuletzt auch den Schein von Authentizität verleiht. Der historische, genauer gesagt mythhistorische Zusammenhang, der in Gestalt der Kekropiden und des Erichthonios zwangsläufig zum Ausdruck kommt und sich in positivistischer Sicht als zeitlicher Widerspruch gegenüber der Aktualisierung erweist, ${ }^{110}$ wird dabei aber nicht grundsätzlich negiert. Das mehrmalige Wiederaufgreifen des Wortbruches der Kekropiden gegenüber Athene macht dagegen kenntlich - unter anderem in Form von nuper (748) als Zeitmarkierung -, was als diegetische Chronologie sonst im Hintergrund mitgedacht, aber im Normalfall unbewusst als gegeben vorausgesetzt wird. Der durch die Aktualisierung repräsentierte extradiegetische Wissensstand steht so einem tatsächlichen, weil explizierten Zustand der diegetischen Welt gegenüber, der wiederum selbst impliziert, dass Erichthonios als Kind noch keine staatstragenden Handlungen vollzogen haben kann. ${ }^{111}$

Von einem offenen Widerspruch durch diesen poetischen Synchronismus kann aber nicht gesprochen werden. Denn gerade dadurch, dass dieser weder expliziert noch auf derselben Wissensstufe geäußert wird, steht er zum einen nicht im Vordergrund, sodass er die diegetische Handlung wesentlich anzweifelt; ${ }^{112}$ zum anderen kommt er aber so deutlich zum Vorschein, dass ein halbwegs mit der mythischen Frühzeit Athens vertrauter Rezipient darauf aufmerksam wird, auch wenn dies nicht zwangsläufig erfolgen muss. ${ }^{113}$

Fällt der in den zeitlichen Implikationen liegende Widerspruch aber auf, tritt hinter der epischen Objektivität ein Erzähler hervor, dessen Primat eindeutig auf der

109 S. o. S. 5, Anm. 21.

110 Und dies betrifft - das sollte nicht vergessen werden - neben der aktualisierenden Schilderung der Panathenäen genauso auch die Munychios agros (709) und culti arbusta Lycei (710).

111 Treffend dazu die Bemerkung bei Zissos/Gildenhard 2004, 55: „The poet offers vestigial traces of vanished cultural signifiers, thereby calling attention to a cancellation of meaning, a failed ,cognitve mapping“ of the polis.“

112 Vgl. zum Gedanken Schmitzer 2006, $32 \mathrm{f}$.

113 Die unzeitgemäße Zeichnung Athens als eine „strategic marginalization of the polis“ (Zissos/ Gildenhard 2004, 71) zu sehen, ist im Ansatz eine vielversprechende Beobachtung, sie würde aber dem diegetischen Geschehen nur mehr eine Statistenrolle zukommen lassen und dem mythhistorischen Aspekt wohl zu viel Geltung verleihen. Weiteres dazu bei Geitner 2019, 137-139. 
Veranschaulichung seines Stoffes liegt und der diese Möglichkeit bis zu einem wortwörtlich grenzwertigen Grad ausreizt. ${ }^{114}$ Denn unter Aufgabe der Illusion einer faktualen Wiedergabe eines vermeintlich verbürgten Geschehens, ${ }^{115}$ tritt als eigentlicher Kern dieser Darstellung - und hierbei schließt sich wieder der Kreis zur Fiktionstheorie - eine Pseudo-Realität hervor, die sich nicht zuletzt auch auf poetische Synchronismen stützt.

\subsection{Ihrer Zeit weit voraus - die Lehren des Pythagoras in met. XV}

Das letzte Beispiel, das in diesem Kapitel besprochen werden soll, ist das bereits in anderem Zusammenhang erwähnte Treffen von Pythagoras und Numa. ${ }^{116}$ Was historisch betrachtet in einem dieses Ereignis faktual wiedergebenden Narrativ einen Anachronismus darstellt, verlangt im Kontext der „Metamorphosen“ eine differenziertere Betrachtung. ${ }^{117}$ Gerade der Umstand, dass die Unmöglichkeit der Zusammenkunft von Numa und Pythagoras in nicht-dichterischen Texten vor (Cicero, Dionysios von Halikarnass) bzw. in etwa gleichzeitig (Livius) zu Ovids Lebens- bzw. Schaffenszeit entschieden proklamiert wurde, verleiht der ovidischen Behandlung eine besondere Relevanz: Trotz oder wohl besser wegen solcher Diskussionen erfolgt sie in genau dieser Form. ${ }^{118}$

114 Einen besonderen Reiz dürfte es für den Dichter Ovid fraglos dargestellt haben, dass sich ein prototypisches Bild von Athen, zu dem symbolträchtige Landmarken, aber eben auch ein gutes Fest gehören, durch genau diejenigen Ereignisse vorwegnehmen lässt, die diegetischen Akteuren zugeschrieben, aber von diesen erst zu einem späteren Zeitpunkt gegründet werden.

115 Darin dürfte das Grundprinzip des „deconstructive pressure“ (Zissos/Gildenhard 2004, 71) liegen. Diese Problematisierung im unmittelbaren Kontext ist dann bestens anschlussfähig für weitergehende Lesarten, nach denen eine Ironisierung des in den literarischen Quellen allzu einmütigen und positiven Lobpreises auf Athen vorliegt, so Barchiesi ${ }^{4} 2013$, ad met. II, 795 f.; oder noch allgemeiner eine intertextuelle Auseinandersetzung mit der griechischen Kultur vom römischen Standpunkt aus stattfindet, so z. B. Zissos/Gildenhard 2004.

116 S. o. Kap. 2.2.1.1.

117 Letzteres gänzlich zu erschließen, muss im Zuge der hier nachgegangenen Fragestellung nicht erbracht werden. Dazu sei verwiesen auf Deutungen von Buchheit 1993, Schmitzer 2006 und die Anmerkungen bei Hardie 2015, ad met. XV, 4-11 und 60-478.

118 Meist wird dies mit dem Be- oder Nachweis der Unmöglichkeit des Treffens als erschöpfend diskutiert erachtet. Wegweisend aber schon die Beobachtungen bei Bömer 1986, ad met. XV, 7 f. Vgl. Buchheit 1993, 84 (Anm. 33). Ob es sich gleich um ,the most famous anachronism in the whole poem, indeed, the most famous anachronism of Roman history“ (Feeney 1999, 22) handelt, ist - über die „Metamorphosen“ hinaus - mit Blick auf Aeneas und Dido durchaus zu bezweifeln. S. dazu Stok 2016, $430 \mathrm{f}$. 


\title{
6.4.1 Ein wirklich wahres Vorspiel - met. XV, 1-59
}

$\mathrm{Zu}$ Beginn des 15. Buches wird Numa vom ,wahrheitskündenden Gerücht' (praenuntia veri fama - 3f.) zum König Roms bestimmt. ${ }^{119}$ Ehe er aber dieser Berufung folgt, gelangt er in seinem Streben nach genauerer Kenntnis der hiesigen Traditionen (ritus - 5) und geleitet von der ur-philosophischen Frage nach dem Wesen der Dinge (quae sit rerum natura - 6) ins süditalische Kroton, umschrieben als die ,Stadt des herkulischen Gastfreundes' (Herculei ad hospitis urbem - 8). ${ }^{120}$ Dort wird ihm zunächst die sagenhafte Gründungsgeschichte der Stadt von einem der älteren Einwohner (e senioribus unus ... indigenis - 10 f.) erzählt, der passenderweise ,der alten Zeit[en] nicht unkundig' ist (veteris non inscius aevi - 11). ${ }^{121}$

Das ist zum einen bemerkenswert, weil Alter in den „Metamorphosen“ eine ambivalente Größe ist und unterschiedslos ein Garant oder ein Vernichter von Erinnerung sein kann, sodass seine Eigenschaft, Wahrheit zu verbürgen, an sich wenig verlässlich ist; ${ }^{122}$ zum anderen aber auch, weil Kroton nach antikem Urteil 720, 710 oder 709 v. Chr. gegründet wurde, also in den letzten beiden Fällen vier bzw. fünf Jahre nach Numas Herrschaftsantritt oder mehr oder weniger gleichzeitig damit. ${ }^{123}$

\begin{abstract}
119 Allerdings ist hier fama weder die personifizierte Gottheit Fama noch wählt sie Numa zum König, wie Gladhill 2013, 314, nahelegen möchte; ganz abgesehen davon, dass die von ihm an dieser Stelle bemühte Verknüpfung von engl. fame mit dem hier ausschließlich als ,Kunde, Gerücht` zu übersetzenden lat. fama unnötig ist, weil das ohnehin starke Nachfolgermotiv, das von ihm mit Blick auf die Augustus-Nachfolge diskutiert wird, dafür schon ausreicht. Die fama an dieser Stelle (met. XV, 3) wird ja, wie Gladhill selbst bemerkt, von der libera fama (met. XV, 853) direkt wiederaufgegriffen. Vgl. Hardie 2015, ad met. XV, 1-4.
\end{abstract}

120 Damit ist der Heros Kroton gemeint, der sowohl der Stadt den Namen gab als auch Herakles bei sich aufnahm; Myskelos dagegen, dessen Geschichte Ovid nachfolgend erzählt, ist der Gründer der Stadt Kroton. $\mathrm{Zu}$ diesen durchaus verwirrenden Verhältnissen, zu deren Erhellung die ovidische Erzählung nur schwerlich etwas beiträgt s. Bömer 1986, $254 \mathrm{f}$. Dies generell als „refuse de la royauté“ (Fabre-Serris 1995, 166) zu deuten, um es dann mit Pythagoras' odium tyrannidis (met. XV, 61) gleichzusetzen, dürfte aber zu gesucht sein.

121 Wie schon praenuntia veri aus Vers 3, das auf das Ende von Vergils fama-Episode in der „Aeneis“ (nuntia veri - Aen. IV, 188) rekurriert, weist auch das veteris non inscius aevi (11) auf eine „Aeneis“Stelle, in der Vulcanus haud vatum ignarus venturique inscius aevi (,nicht der Seher[sprüche] unkundig und unwissend der künftigen Zeit‘ - Aen. VIII, 627) genannt wird. S. dazu Hardie 2015, 478f.

122 Vgl. Bömer 1969, ad met. I, 400 und Bömer 1986, ad met. XV, 623. Erinnert sei auch an die Wahrhaftigkeit von Nestors aus dessen Munde stammender Altersangabe. S. o. Kap. 5.1.1.2c.

123 Vgl. bes. Knox 1986, 67 f. und Hardie 2015, 479 (ad met. XV, 4-11). Dionysios von Halikarnass

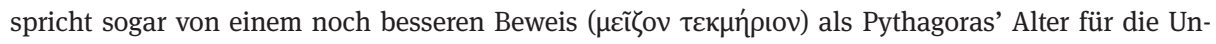
möglichkeit einer Begegnung mit Numa, dass es bei Numas Herrschaftsantritt die Stadt Kroton, in der

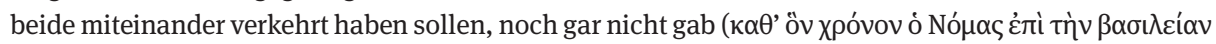

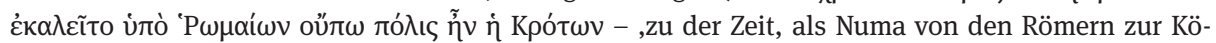
nigsherrschaft berufen wurde, gab es die Stadt Kroton noch nicht ${ }^{*}$ - Dion. ant. II, 59, 3). Allerdings wird im RE-Artikel wohl zurecht angemerkt, dass „die genaueren Angaben [...] wertlos“ (Philipp 1922, 2020) nach heutigen Maßstab sind; eine Argumentation wie sie Cole 2004, 143f. (Anm. 141), aufbauend auf einer solchen Rechnung führt, ist daher wenig hilfreich, gleichfalls dessen Verweis auf Fontenrose 
Der typisch aitiologische Verweis auf das Alter des Sprechers, um dessen Worten hier sogar unter Betonung von dessen Erinnerungsgabe - größeres Gewicht zu verleihen, ${ }^{124}$ entpuppt sich so wiederum als eine vermeintlich unscheinbare Erzähleraussage, die genauer besehen zeitlich unmöglich oder, nimmt man das in Ps.Skymnos bezeugte Datum 720 v. Chr., ${ }^{125}$ mindestens irreführend ist. ${ }^{126}$

Das Besondere an diesem poetischen Synchronismus ist aber, dass durch die Implikation, die sich aus dem Alter des Mannes und seiner Kunde von den alten Zeiten ergibt, die ohnehin schon gegebene historische Unmöglichkeit mit der Plausibilität der eigenen Chronologie überspielt wird, sodass man natürlicherweise annimmt, die Gründung Krotons müsste schon länger zurückgelegen haben. ${ }^{127}$ Die Binnenerzählung, in welcher Herakles zum einen im Traum erscheint und zum anderen Wunder wirkt, büßt dann zwar an Historizität ein, sie gewinnt aber durch diese Fernstellung zugleich an Glaubwürdigkeit als mythisches und diegetisches Ereignis, ${ }^{128}$ wenn sie diesem Anspruch entzogen ist, nach historischen, d. h. faktischen Maßstäben beurteilt werden zu müssen. ${ }^{129}$ Eingeführt ist die Stadt immerhin mit der Umschreibung als Herculei hospitis urbem (8), womit sie klar mit der mythischen und nicht mit der historischen Welt $-d$. h. mit der griechischen Kolonisation im späten achten Jahrhundert v. Chr. - in Verbindung zu bringen ist.

Vor eben diesem Hintergrund müssen auch die darin erwähnten Städte betrachtet werden, an denen, wie der alte Mann erzählt, Myskelos von Griechenland kommend vorüberfährt:

1978, 138, der Coles eigenem Einwand (Gleichzeitigkeit der Gründungen von Syrakus und Kroton) sogar widerspricht (denn diese Gleichzeitigkeit, so Fontenrose, „,belongs to a kind of fable“). Doch wie dem auch sei, der Erzähler - und das ist zur Bewertung der „Metamorphosen“-Stelle zuallererst entscheidend - ist ein alter Mann, der sich in den alten Zeiten auskennt.

124 Vgl. Myers 1994, 81f. Eine Übersicht zu „alten“ intradiegetischen Erzählern bietet Nikolopoulos 2004, 165-169.

125 Skymn. 359.

126 Diese bestätigt der intradiegetische Erzähler typisch ovidisch in ihrer zeitlichen Geltung noch damit, dass er einerseits Myscelus illius dis acceptissimus aevi (,der in jener Zeit den Göttern willkommenste - 20) nennt. Vgl. den Hinweis bei Barchiesi 2001, 63. Andererseits wird die angebliche Historizität implizit auch damit unterstrichen, dass hier wie schon bei den Panathenäen eine auf einer Aktualisierung beruhende Tradition in Myskelos' Heimatstadt erwähnt wird, die von alters her bestand (mos erat antiquitus - 41). Zum weiteren Kontext s. Hardie 2015, ad loc.

127 Auch Bömer spricht mit Verweis auf diese Stelle vom „Schein besonderer Altertümlichkeit“ (Bömer 1986, ad met. XV, 435f.). Indem hier zwei mehr oder weniger gleichzeitige Ereignisse voneinander entfernt werden, träfe auch eigentlich die Bezeichnung „Synchronismus“ gar nicht mehr zu. Der Definition nach kann aber weiterhin von einem poetischen Synchronismus gesprochen werden.

128 Herakles ist trotz seines Wiederauftauchens im elften Buch nach Ovids eigener Erzählung (met. IX, 271f.) immerhin ein Sternbild, wodurch sein Handeln, d. h. auch seine Einkehr bei Kroton, besser in eine ferne, historisch wenig bestimmbare Zeit passt.

129 So nennt auch Segal 2001, 71, den Inhalt „a purely mythical event“. 
ventisque faventibus aequor

navigat Ionium, Lacedaemoniumque Tarentum

praeterit et Sybarin Sallentinumque Neretum

[50]

Thurinosque sinus Nemesenque et Iapygis arva. ${ }^{130}$

Ohne auf die konkreten Probleme bei der Geographie eingehen zu wollen, ${ }^{131}$ gelten in zeitlicher Hinsicht dieselben Prämissen wie bei Kroton: Die genannten Städte dürften im Zuge der griechischen Kolonisation entweder grob zur selben Zeit wie Kroton oder erst wesentlich später gegründet worden sein, sodass sie zum Zeitpunkt, als der alte Mann diese Geschichte aus alten Zeiten berichtet, noch nicht bzw. noch nicht unter dieser Bezeichnung existiert haben. ${ }^{132}$ Dass er zudem Tarent als ,lakedaimonisch', Neretum als ,sallentisch' und eine Meeresbucht als ,thurinisch' zu bezeichnen weiß, verdeutlicht diese zeitliche Inkonsistenz nur noch mehr, da die Epitheta aus der Perspektive eines intradiegetischen Erzählers geäußert werden, aber dem Wissensstand des Primärerzählers entsprechen. Neben der prinzipiellen Problematik bei der Verwendung solcher Attribute ist dieses trügerische Zeitverhältnis daher durch die Perspektive des intradiegetischen Erzählers noch gesteigert: ${ }^{133}$ Beispielsweise ist der ohnehin schon problematische Eigenname Tarentum durch sein Beiwort Lacedaemonium (50), das daran erinnert, dass Sparta auf dem griechischen Festland die Mutterstadt ist, noch enger in Beziehung gesetzt zum realen Tarent und seiner Gründungsgeschichte. Diese dürfte aber weder der alte Mann kennen noch in einer zu imaginierenden diegetischen Realität eigentlich relevant sein.

Bei der Myskelos-Episode werden daher Ereignisse, die zur diegetischen Gegenwart sehr wahrscheinlich noch nicht hätten stattfinden können, durch die Charakterisierung des Binnenerzählers und dessen Darbietungsweise mit einem Abglanz von einer fernen Zeit versehen, der so plausibel ist, dass die zeitlichen Widersprüche einen Rezipienten nicht dazu auffordern dürften, sie „unters Skalpell nehmen“134 zu wollen. Als Historiker wird ein solcher Erzähler kaum eine Autorität zu nennen sein, aber als überzeugender, weil fiktional ausgestaltender Berichterstatter allemal. ${ }^{135}$

130 Met. XV, 49-52: ,Und unter günstigen Winden segelt er auf dem Ionischen Meer und fährt vorbei am lakedaimonischen Tarent und Sybaris und dem sallentinischen Neretum und der Bucht von Thurioi und Nemese und den Fluren des Iapyx.

131 Darauf, die Anordnung der Städte als willkürlich zu erweisen, ist bereits viel philologischer Eifer gewendet worden. Vgl. Bömer 1986, 264-267.

132 S. dazu die Angaben ebd., ad loc. und Ebert 1888, 34.

133 S. o. Kap. 5.2.

134 Bömer 1986, 266.

$135 \mathrm{Zu}$ einem ähnlichen Schluss kommt Granobs 1997, 28f. Äußerst relevant ist es, dass diese Gründungsgeschichte vor dem Hintergrund der schreiend verschwiegenen Gründung Roms im Buch zuvor betrachtet werden muss. Treffend dazu Feeney 1999, 22: „And the secure significance of this foundation-date [sc. of Rome; Anm. d. Verf.] is practically immediately undermined by the beginning of the next book, when we get a really proper elaborate foundation story, the foundation of ... Croton.“ 
Dieser Aspekt wird dadurch betont, dass der Primärerzähler Ovid nach Abschluss des intradiegetischen Berichts wortwörtlich noch hinzusetzt, dass es aufgrund einer ,sicheren Kunde، (certa fama - 58) ${ }^{136}$ festgestanden habe (constabat - 58), dass die Gründung der Stadt so verlaufen sei (talia primordia esse - 58f.). Das ostentative Bekräftigen der Glaubwürdigkeit der sehr vage charakterisierten Quelle einerseits und der Wahrhaftigkeit des Erzählten andererseits ist sicherlich an sich schon auffällig und lässt berechtigte Zweifel aufkommen, ob etwas, das mit einer solchen Energie als wahr auszuweisen versucht wird, sich in der Tat dann so verhält. ${ }^{137}$ Die einzige sichere Gewähr liefert der eben dargebotene Bericht selbst, seine Wahrheit aus diesem zu folgern und sie gegenüber dem Leser zu behaupten, beruht somit auf einem klassischen Zirkelschluss. ${ }^{138}$

Hinzu kommt noch, dass bei der Junktur certa fama der Widerspruch in sich sowie gegenüber constabat wohl ungeachtet dessen, wie man dies genau übersetzt, nie ganz aufzulösen ist: Zum einen ist es eine Grundeigenschaft von fama, dass sie eben nicht certa ist und deswegen nach dem Grad der Wahrscheinlichkeit zusätzlich als unmöglich, möglich oder sicher qualifiziert werden kann bzw. muss; und zum anderen besteht ein erheblicher sprachlogischer Unterschied zwischen einer Tatsache, $d . h$. einer Wahrheit, wie sie von constare behauptet wird, und einer fama, deren Inhalt höchstens sehr wahrscheinlich, aber nie an und für sich wahr sein kann. ${ }^{139}$ Überdies kann die syntaktische Offenheit bei der ablativischen Angabe certa fama, die sowohl auf das übergeordnete Prädikat constabat (,es stand fest wegen sicherer Kunde`) als auch auf den Infinitiv des davon abhängigen AcI-Satzes bezogen werden kann (es stand fest, dass solchermaßen die Anfänge nach sicherer Kunde sind'), zusammen mit den zwei Hyperbata talia ... primordia und certa ... fama (beide 58) diesem Erzählerkommentar insgesamt wohl nur schwerlich eine letztgültige Eindeutigkeit verleihen. Indem Ovid schließlich die Aussage von constare zusätzlich in die - diegetische Vergangenheit verlegt, distanziert er ihre Gültigkeit von seinem eigenen, extradiegetisch gegenwärtigen Standpunkt, von dem aus er berichtet. ${ }^{140}$

Nicht unwichtig ist es daher zunächst zusammenfassend festzuhalten, wie sehr Ovid mit dieser Bemerkung am Ende der Myskelos-Geschichte den Blick auf die an-

136 Je nach dem, mit welcher Konnotation man das lateinische fama übersetzen möchte, reicht das Bedeutungsspektrum laut OLD von ,news, tidings‘ über ,rumour, hearsay‘ und ,tradition, story bis zu

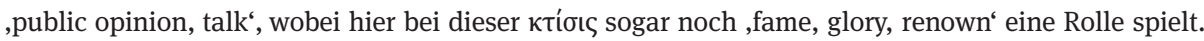
137 Vgl. dazu Koschorke 2012, 88f. Zum Thema Aitiologie und unzuverlässiges Erzählen s. Kirstein 2019a, $203 \mathrm{f}$.

138 Vgl. Rosenkranz 2006, 205 f.

139 Das dürfte auch nachvollziehbar sein, ohne in einer über mehr als zwanzig Verse reichenden Fama-Allegorie gelesen zu haben, dass sich in deren Haus die Personifikationen unter anderem der Leichtgläubigkeit (Credulitas - met. XII, 59) und des Irrtums (Error - ebd.) aufhalten. Vgl. met. XII, 39-63. S. dazu Hardie 2002a, 70 - 77, der den credulitas-Aspekt mit der oben besprochenen „Amores“Stelle und Ovids Poetik in Verbindung bringt. S. o. Kap. 3.1.2.

140 Würde er dies mit einem constat (,es steht fest') beschreiben, hätte er damit die Gültigkeit der Aussagen noch in seiner Gegenwart impliziert. 
schließende Numa-Pythagoras-Episode prägt: „come la storia di Numa e Pitagora, la certa fama (58) della storia di Miscelo fondatore dipende del tutto dagli autori di testi.“141

\subsubsection{Formale und thematische Parallelen der intradiegetischen Erzählungen met. XV, 9-59 und met. XV, 60-479}

Ausgehend davon überrascht es kaum, wie sehr die Myskelos-Episode nicht nur wortwörtlich den Grund für den Pythagoras-Monolog bereitet, weil sie die Lokalgeschichte des Schauplatzes, der Stadt Kroton, beleuchtet, sondern außerdem als ein wichtiges „narratives Scharnier“142 fungiert und die Kommunikationssituation der anschließenden Rede in mehrfacher Weise präfiguriert. Unmittelbar im Anschluss an Ovids Bekräftigung der certa fama von Krotons Gründungsmythos wird nämlich der nächste Erzähler eingeführt:

vir fuit hic ortu Samius, sed fugerat una

et Samon et dominos odioque tyrannidis exul

sponte erat. isque licet caeli regione remotos

mente deos adiit et quae natura negabat

visibus humanis, oculis ea pectoris hausit.

cumque animo et vigili perspexerat omnia cura,

in medium discenda dabat coetusque silentum

dictaque mirantum magni primordia mundi

et rerum causas et quid natura docebat,

quid deus, unde nives, quae fulminis esset origo,

Iuppiter an venti discussa nube tonarent,

[70]

quid quateret terras, qua sidera lege mearent,

et quodcumque latet. primusque animalia mensis

arguit imponi, primus quoque talibus ora

docta quidem solvit, sed non et credita, verbis: ${ }^{143}$

141 Hardie 2015, 479.

142 Oberrauch 2005, 117. Scheinbar ist dies so selbsterklärend, dass diese Parallelen bislang kaum thematisiert wurden, abgesehen von allgemeinen oder vereinzelten Bemerkungen (u. a. bei Bartenbach 1990, 224-226; Tronchet 1998, 238; Barchiesi 2001, 62-64 oder passim bei Hardie 2015).

143 Met. XV, 60-74: ,Hier gab es einen Mann samischer Abkunft, er war aber geflohen sowohl aus Samos als auch vor den Herrschern und war aus Hass gegenüber dem Tyrannen in freiwilligem Exil. Und dieser trat an die Götter, obschon von ihm abgesondert in der Himmelregion, im Geiste heran und nahm mit seinem inneren Auge das in sich auf, was die Natur menschlichem Anschauen verweigerte. Und als er alles mit Geist und wachsamer Sorge durchblickt hatte, da stellte er es zur Erlernung allgemein zur Verfügung und lehrte die Versammlungen Schweigender und die Worte Bestaunender die Anfänge der großen Welt und die Ursachen der Dinge und, was Natur, was Gott, woher Schneefall, was der Ursprung des Blitzes sei - ob Jupiter oder Winde bei zersprengter Wolke donnerten -, was die Länder erschüttere, nach welcher Regel die Sterne wanderten, und was sonst noch verborgen ist. Und als Erster erwies er es als falsch, Lebewesen zu Tische zu servieren, als Erster auch öffnete er seinen Mund, gelehrt zwar, aber nicht auch einer, dem geglaubt wird, zu solcherlei Worten.' 
Ist der erste intradiegetische Erzähler ein namenloser alter Einwohner, ist es hier ein namenloser samischer Exilant (vir ortu Samius ... exul - 60f.). Zugleich wird damit auch das Motiv des Heimatverlusts bei Myskelos bzw. der Heimatferne bei Numa (patria Curibusque relictis - 7) wiederaufgegriffen. ${ }^{144}$

Wie der Greis durch die erste Binnenerzählung das eine der beiden Reisemotive Numas (non ille satis cognosse ... habet ritus - 4f.) exemplarisch mit einem Gründungsmythos befriedigt, ${ }^{145}$ ist der zweite Erzähler der ideale Gesprächspartner für das andere Motiv - die Frage quae sit rerum natura (6) -, wenn er unter anderem mit magni primordia mundi, rerum causas und quid natura (67f.) aufwarten kann. ${ }^{146}$

Berichtet der erste Erzähler nur die regionalen primordia ... loci positaeque ... urbis (58f.), sind diese dann beim zweiten als magni primordia mundi (67) wiederaufgegriffen und in eine im eigentlichen Sinn globale Dimension und im übertragenen philosophische gerückt. ${ }^{147}$

Und wird der erste Bericht mit der extradiegetischen Kommentierung unter anderem durch den Verweis auf die certa fama explizit in seinem Wahrheitsgehalt (dis-) qualifiziert, wird dies um nichts weniger auch beim zweiten Sprecher vorgenommen, dort allerdings zum Teil schon im Voraus: Heißt es nicht von seinem Mund - die Metonymie für eine „Aussage“ schlechthin -, er sei zwar gelehrt (docta - 74), aber nicht auch einer, der Glauben finden konnte (non et credita - ebd.), anders gesagt einer, der von seinen Zuhörern als unglaubwürdig empfunden worden ist. ${ }^{148} \mathrm{Ob}$ nun sichere fama oder ein Mund, dem nicht geglaubt wird - feststeht, dass in beiden

144 Bei Pythagoras wie auch bei Numa freiwillig, bei Myskelos unfreiwillig. Vgl. Bartenbach 1990, 225. Für die autobiographische Lesart in Bezug auf Ovids eigenes Exil s. McGowan 2014, 191-197.

145 Auch wenn in der „Metamorphosen“-Stelle nur von den Sabinae gentis ritus (4f.) die Rede ist, dürfte dies Italien im Allgemeinen bedeuten, d. h. die Lokalgeschichte, Gebräuche etc. nicht nur der Sabiner. Die müsste Numa als Sabiner ja eigentlich kennen. S. dazu unten Kap. 6.4.4 und Bömer 1986, $249 \mathrm{f}$.

146 So auch Due 1974, 30. Vgl. zudem Buchheit 1993, 86 und Hardie 2015, ad loc.: „un tipico elenco di questioni scientifiche“.

147 Dies ist bei primordia aber weniger ein „abrupt shift of the meaning“ (Segal 2001, 72), als schlicht seine Erweiterung, unterstrichen von der kontextuellen Nähe und der syntaktischen Gleichheit der Nominalgefüge: Zweimal ist es nominaler Kern für ein Genitivattribut, das in beiden Fällen räumlich verstanden werden kann (Kroton im Kleinen, der Kosmos im Großen), wobei dann bei letzterem noch die universelle Bedeutung hinzukommt. Und besonders durch den räumlichen Aspekt kann die gegründete Stadt, bei der nicht weniger auch Rom mitgedacht werden soll, so in direkte Beziehung zu ihrer Weltherrschaft gesetzt werden, wie es im 15. Buch immer wieder angesprochen wird. Vgl. dazu Hardie 2015, ad met. XV, 12-59 und 447-449.

148 Vgl. Wheeler 1999a, 190, der das non et credita zu Pythagoras' späterer Aussage fama est (431) in Beziehung setzt, die (es ist die Rom-Prophetie) von Ovids Zeitgenossen verifiziert werden kann, und fügt hinzu: „Although the narratorial audience can verify the truth of the rumor, the Ovidian narrator goes out of the way to call attention to its dubiousness.“ Vgl. auch (mit Fokus auf den Status der Rede als Lehrdichtung) Barchiesi 2001, $64 \mathrm{f}$. 
Fällen ein gewisser Zweifel an der Wahrheit der Aussage zum Ausdruck gebracht bzw. zugelassen wird. ${ }^{149}$

Dass sich der Primärerzähler nach Beendigung beider Reden mit talia (58) bzw. talibus (479) wieder einschaltet, ist zwar nicht ungewöhnlich, ${ }^{150}$ gewinnt aber doch angesichts dieser destabilisierten Autorität der intradiegetischen Erzähler an Relevanz: als eine weitere, wenn auch unscheinbare Strukturparallele zum einen, aber insbesondere als ein zusätzliches Moment der Abschwächung zum anderen. Dass dieses talia (58) nach der Myskelos-Episode neben dem im selben Vers stehenden Widerspruch bei constabat und certa fama sehr gut zu der offensichtlich vermiedenen Gewissheit beiträgt, ist bereits angesprochen worden. Noch deutlicher aber dürfte das dann bei der Pythagorasrede sein, bei der das bereits an ihrem Anfang stehende talibus ... verbis (73f.) am Ende mit talibus wiederaufgegriffen und mit dem Zusatz atque aliis ... dictis (,durch derlei und andere Worte ${ }^{6}$ - 479) sozusagen verwässert wird. ${ }^{151}$ Zudem kommt der nach der ersten Erzählung mit fama (58) anklingende Aspekt des Hörensagens und der schon mit dem non et credita (74) laut werdende Zweifel an der Autorität des intradiegetischen Erzählers nach der zweiten Rede gleichfalls, aber auf deutlichere Weise durch ferunt (,man überliefert, es heißt' - 480) zur Geltung, in dessen syntaktischer Abhängigkeit unter anderem talibus (479) steht. ${ }^{152}$

Ovid hebt also im einen Fall bei einer nach antikem Maßstab klassischen fabula dessen certa fama hervor und erweckt den - auf zweifelhaftem Grund stehenden Anschein von Faktizität, verweist aber im anderen Fall mit ferunt auf eine äußerst unspezifische Tradition und vermeidet als Erzähler eine explizite Positionierung gegenüber der Wahrhaftigkeit des aus zweiter Hand Berichteten, sei sie nun affirmativ oder bezweifelnd. ${ }^{153}$

Dies führt zur letzten Parallele bei den beiden Erzählern: Wie es ein poetischer Synchronismus ist, dass ein alter Mann den Gründungsmythos einer Stadt erzählt, die es entweder noch nicht gibt oder von der Numa, wenn sie während seiner Herrschaft gegründet worden wäre, in seinem Wissensdrang bestimmt schon vorher erfahren

149 Für die historischen und metapoetischen Bezüge s. Hardie 2015, ad met. XV, 72-74. Vgl. zudem die Bemerkung zum unzuverlässigen Erzählen bei Kirstein 2019a, 205.

150 Weitere Stellen finden sich u. a. bei Bömer 1969, ad met. II, 783 und Bömer ²2008, ad met. VII, 661. 151 Vgl. Galinsky 1998, $320 \mathrm{f}$.

152 Vgl. hierzu Wheeler 1999a, 127: ,the narrator distances himself from the ,truth' of what he says by attributing it to tradition (,ferunt')“. Die Feststellung von Segal 2001, 71, ist durchaus richtig, dass certa fama eindeutig gegenüber Pythagoras' Stimme abgesetzt ist. Dass sich aber das prätentiöse Bekräftigen einer certa fama, die sich wohl kaum ausreichend als ovidische Quellenangabe bezeichnen lassen kann, mit ferunt nach der Pythagoras-Rede überschneidet, ist ebenso wichtig zu berücksichtigen.

153 Interessant ist hierzu auch die Feststellung bei Bömer 1986, ad met. XV, 435f., dass eine wie bei ferunt ausgedrückte „vorsichtige Distanzierung (besonders oft bei Pythagoras)“ vorkommt. Näheres dazu bei Miller 1994. 
hätte, ${ }^{154}$ so ist es bekanntlich ein noch viel prominenterer poetischer Synchronismus, dass ein Philosoph, der nach historischen Maßstäben deutlich später als Numa lebt, sich in dieser wortwörtlich utopischen Stadt befindet und seine Lehren weitergibt, wobei auch Numa zugegen ist. ${ }^{155}$

Dass es sich dabei aber um ein in den Grenzen der diegetischen Welt wahres Ereignis handelt, ist Ovid nicht wenig bemüht, auch bei Pythagoras zu unterstreichen. Schon dem Tempusgebrauch ist dieses Streben nach einer glaubwürdigen Einbettung der Reden abzulesen: Im Perfekt steht sowohl, dass der alte Mann ,berichtet hat (rettulit - 11), als auch, dass der Mann aus Samos sich ,hier', d. h. in Kroton, ,befunden hat' (fuit hic - 60). ${ }^{156}$ Andere Informationen im Zusammenhang mit den Reden, mit denen ein länger währendes oder eher hintergründiges Detail ergänzt wird, sind konsequent mit Imperfekt oder Plusquamperfekt abgesetzt: so bei constabat (58) nach Krotons Gründungsgeschichte und bei Pythagoras in Form von fugerat (60), erat (62), negabat (63), perspexerat (65), dabat (66) und docebat (68). Angesichts einer solchen Fülle an Einzelaspekten, in deren Vordergrund die im Perfekt gehaltene Haupthandlung steht, scheint ein grundsätzlicher Zweifel an der Authentizät der Situation des zweiten Redners nicht angebracht.

\subsubsection{Ovids Darstellung der Kommunikationssituation bei der Pythagorasrede}

Das kleine Narrativ steckt somit den erzählerischen Rahmen der sowohl quantitativ als auch qualitativ-thematisch größeren und wichtigeren Rede ab und konsolidiert die Botschaft, die darin mitgeteilt werden soll. Unter Berücksichtigung der wesentlichen Unterschiede zwischen beiden Binnenerzählungen und unter Beachtung der sonst noch beachtenswerten Besonderheiten der Pythagorasrede, erweist sich aber auch hier ein absolutes Für-Wahr-Halten der Aussagen des extradiegetischen Erzählers als trügerisches Unterfangen.

Dies beginnt schon damit, dass zwar, obwohl beide intradiegetischen Erzähler namenlos sind, der vir ortu Samius (60) über die ihm zugeschriebenen Eigenschaften unmissverständlich mit der historischen Persönlichkeit Pythagoras assoziiert werden

154 In diesem Falle bräuchte es wohlgemerkt auch keinen Erzähler, der sich durch seine Kenntnis alter Zeiten auszeichnet.

155 Auf diese Parallele weisen u. a. auch Knox 1986, 66f. und Barchiesi 2001, 63f., hin, obschon die Bemerkung von Letzterem, Numa ,asks about the achievements of someone yet to be born“ (64), einen falschen, zur eigentlichen Gestaltung konträren Eindruck vermittelt, da Numa weder als fragendes Subjekt hinsichtlich der Gedanken von Pythagoras auftritt noch sich in anderer Weise direkt auf diesen bezieht. Ebenso irreführend auch Deremetz 2013, 234: „Ovid [...] presents Numa as listening to Pythagoras’ teaching“. Dazu lakonisch-treffend Bömer 1986, 253: „Kein Wort von einer persönlichen Begegnung“.

156 Die Ereignisse, so die Implikation, haben in der Diegese, wie sie zum Zeitpunkt der Handlung beschaffen ist, stattgefunden und können vom Standpunkt des extradiegetischen Erzählers als abgeschlossen gekennzeichnet werden. Zum Perfekt bei adiit (63) und hausit (64) s.u. Kap. 6.4.4. 
kann. ${ }^{157}$ Ähnlich wie schon bei den Panathenäen wird somit auch hier ein fiktives Objekt durch eindeutige Charakteristika als dasjenige Objekt wahrnehmbar, das es in der außertextlichen Realität ist, ohne bei seinem Namen genannt zu werden. ${ }^{158}$ Die Aussage, mit der die Existenz von Pythagoras in der fiktiven Welt behauptet wird, ist daher gleichfalls in gewisser Weise abgeschwächt bzw. „vorsichtig“159 formuliert, weil die letztgültige, $d$. h. namentliche Determination nicht erfolgt.

Und wie beim Panathenäen-Synchronismus das korrespondierende fiktive Objekt Erichthonios aus der diegetischen Wahrnehmung verdrängt, aber seine Existenz wachgehalten wird, ist dies auch hier der Fall: Numa wird zwischen der ersten und der zweiten Binnenerzählung weder direkt noch indirekt erwähnt und taucht erst am Ende der Pythagoras-Rede wieder in dem zum Teil schon erwähnten Abschlusskommentar des extradiegetischen Erzählers auf:

talibus atque aliis instructum pectora dictis

in patriam remeasse ferunt ultroque petitum

accepisse Numam populi Latialis habenas; ${ }^{160}$

[480]

Die oben festgestellte Distanzierung Ovids von der Wahrhaftigkeit des Redeinhalts durch talibus atque aliis ... dictis (479) und ferunt (480) verschleiert somit außerdem eine in der Diegese vermutlich stattfindende Interaktion Numas mit Pythagoras. Denn letzterer ist allenfalls metonymisch in dem ohnehin vagen talibus ... dictis greifbar und untersteht der gleichen von ferunt verbalisierten Unverbindlichkeit. So undeutlich die Beziehung der beiden Figuren am Ende der Rede ist, so suggestiv wird diese zu Beginn hergestellt, wenn man sich die letzte explizite Erwähnung Numas vor Augen führt, für die auch die Parallele der beiden Binnenerzählungen wieder beachtenswert ist. In Kroton angekommen, erkundigt sich dieser nach dem Gründer der Stadt, was Ovid folgendermaßen erzählt:

quaerenti sic e senioribus unus

rettulit indigenis, veteris non inscius aevi: ${ }^{161}$

$157 \mathrm{Zu}$ weiteren Aspekten bezüglich dieser Anonymität s. Hardie 2015, ad met. XV, 60-62. Noch knapper, aber ebenso eindeutig wird Pythagoras in den „Fasten“ als Samius und qui posse renasci/ nos putat (,der glaubt, dass wir wiedergeboren werden können“ - Ov. fast. III, 153f.) charakterisiert.

158 Konsequenterweise müsste daher Tarrant 2004 in der „Metamorphosen“-Ausgabe, wenn er Pythagoras im Index Nominum in Klammern gesetzt aufführt, das Lemma hierzu lautet: „(Pythagoras sapiens 15. 60)“, auch die Panathenäen auf dieselbe Weise kennzeichnen. Diese bleiben aber anders als andere in den „Metamorphosen“ namentlich erwähnte Feste unerwähnt.

159 Bömer 1986, 254.

160 Met. XV, 479-481: ,Von derlei und anderen Worten im Geiste unterrichtet soll Numa in die Heimat zurückgekehrt sein und die Leitung über das latinische Volk angenommen haben, das ihn von sich aus darum gebeten hatte.

161 Met. XV, 10 f.: ,dem Fragenden berichtete so einer der älteren Einwohner, der alten Zeiten nicht unkundig. 
Numa als Fragender ist hier - die Syntax des Satzes lässt daran keinen Zweifel - der Adressat der nachfolgenden Binnenerzählung. Die Gesprächssituation ist damit sowohl lokal als temporal in der fiktiven Umgebung verankert. Weil diese Situation aber nach dem Ende der ersten Rede nicht mehr aufgegriffen oder -gehoben wird, wodurch eine Veränderung signalisiert wäre, sondern nur der Inhalt mit dem Erzählerkommentar bezüglich der certa fama (58) bewertet wird, fordert die nahtlos anschließende Einführung des vir ... ortu Samius (60) dazu auf, sich Numa noch immer als gegenwärtig und als Zuhörer auch der zweiten Rede vorzustellen. Er ist „temporarily out of the picture, but implicitly present as an auditor“162. Dass er aber tatsächlich anwesend ist und zuhört, wird weder bejaht noch verneint, vielmehr wird ein Leser mit der Implikation, die das beredte Schweigen des Erzählers veranlasst und die eben erarbeiteten strukturellen Parallelen nachhaltig unterstreichen, allein gelassen. ${ }^{163}$

Dieser Ambiguität steht dann die eigentliche Einleitung der Rede in nichts nach. Die Behauptung, Pythagoras sei der erste Verfechter des Vegetarismus (met. XV, 72f.), obwohl diese Tradition mit Sicherheit älter war und auch inhaltlich für die Person des Pythagoras nicht wenig kontrovers ist, ${ }^{164}$ fällt gemessen daran, dass er, historisch betrachtet, an einem Nicht-Ort steht und selbst nicht-seiend ist, noch nicht sonderlich ins Gewicht.

Wie dann aber dieses primus (72), das ihn zu dieser Mahnfigur macht, genau verstanden werden muss, ist wegen des zweiten primus (73) durchaus diskussionswürdig. ${ }^{165}$ Übersetzt man nämlich beide auf die naheliegende Weise als prädikative Ergänzung zum Subjekt - ,Er tat es als Erster - dann ist die erste Aussage bezüglich des Vegetarismus, wie eben gesehen, zwar in historischer Sicht zeitlich widersprüchlich, aber hinsichtlich der Satzsemantik in sich stimmig; die zweite Aussage allerdings - dass er als Erster seinen gelehrten, aber unglaubwürdigen Mund zu solchen Worten geöffnet hat - wäre gänzlich inhaltsleer. ${ }^{166}$ Es scheint deshalb nicht unangebracht, eine andere, grammatikalisch ebenso mögliche Variante in Erwägung zu ziehen, nämlich primus als prädikative Angabe aufzufassen und es auf den Verbalvorgang zu beziehen: ,Er tat es zum ersten Mal‘. Dann hätte er in der diegetischen

162 Barchiesi 2001, 64. Auf eine Verbindung vom schweigenden Numa und der pointiert anspielungsreichen ,Zusammenkunft der Schweigenden` (coetus silentum - met. XV, 66), was sowohl der eigentliche Ausdruck für die Seelen in der Unterwelt ist - „, beinahe eine Eulenspiegelei“ Ovids (Bömer 1986, ad loc.) - als auch die in schweigender Ehrfurcht zuhörenden Schüler meint, weist Galinsky 1998, 318 f., hin.

163 Ungenau ist es, dies als „explicit recourse to anachronism“ (Rosati 2002, 280) zu bezeichnen, da weder die erzählerische Darbietung etwas expliziert, z.B. in Form eines Kommentars, noch der als Anachronismus verstandene Synchronismus expliziert wird.

164 S. dazu Bömer 1986, ad met. XV, 75 f.

165 Die Beurteilung als Verstärkung, wie ebd., ad loc. kommentiert, ist nicht hilfreich, wenn nicht erklärt wird, welcher Aspekt genau verstärkt werden soll. Ebenso ist Lukrez als Metatext, auf den Hardie 2015, ad loc. hinweist, ein wichtiger, aber ein für die Bedeutung der unmittelbaren Textaussage zunächst sekundärer Kontext.

166 Wer sonst hätte ihm in dieser Tätigkeit voraus sein können bei einem so beschriebenen Mund? 
Gegenwart zum ersten Mal gegen den Fleischkonsum argumentiert und zum ersten Mal auch eine solche Rede gehalten, wie sie dann dargebracht wird. ${ }^{167}$ Für das zweite primus wirkt die Übersetzung als Prädikativangabe sogar plausibler, da sich so der Widerspruch zwischen dem persönlich mit Pythagoras zusammenhängenden Objekt ora docta ..., sed non et credita (73f.) und der Allgemeinheit der Aussage, dass er etwas als Erster getan hätte, vermeiden lässt. Außerdem hebt es die Einzigartigkeit der nachfolgenden Rede nochmals hervor, wenn über sie behauptet wird, sie sei zum ersten Mal in dieser Form erfolgt. ${ }^{168}$ Die nicht zu übersehende Ähnlichkeit - Position im Satz am Anfang, im Vers nach der Penthemimeres; in der Folge ein ähnlich klingendes -que und quoque (72f.) - täuscht folglich eine syntaktische Gleichheit nur vor, während die identische Übersetzung beider Wörter entweder als Prädikativergänzung oder -angabe zu keinem vollkommen zufriedenstellenden Ergebnis führt. ${ }^{169}$

Nimmt man diesen Aspekt, dass sich das zweite primus hauptsächlich auf die unmittelbar gegenwärtige Gesprächssituation bezieht, einmal als gegeben an, könnte der Formensynkretismus der beiden Prädikate - sowohl arguit (73) als auch solvit (74) drücken unterschiedslos die dritte Person Präsens und dritte Person Perfekt aus zusätzlich von Bedeutung sein. Eine genaue Festlegung des Tempus wird dadurch erschwert, dass in den Sätzen selbst eine definitive temporale Markierung fehlt. ${ }^{170}$

Die Einführung des Pythagoras als Sprecher, die nach dem die erste intradiegetische Erzählung abschließenden und mit constabat (58) im Imperfekt gehaltenen Erzählkommentar folgt, setzt bekanntlich im Perfekt ein (vir fuit hic - 60) und die meisten Informationen über ihn sind im Imperfekt oder Plusquamperfekt gehalten (61-72). Da es überdies als Standardmodus epischen Erzählens bezeichnet werden kann, dass von vergangenen Ereignisse berichtet wird, steht einer fortgesetzten Anwendung dieses Zeitregisters nichts entgegen, auch wenn es an den finiten Verben des Satzes - arguit und solvit - nicht klar fixiert werden kann. Auffällig ist es dann aber, dass mit latet (72) das letzte Wort vor der Redeeinleitung eine indikativische Präsensform ist und mit dessen Nennung die Reihe der obliquen Konjunktive - esset (69),

167 Das wäre beim ersten Prädikat arguit (73) die unwahrscheinlichere Lösung, da vorher schon von der im Imperfekt berichteten Lehrtätigkeit (docebat - 68) gesprochen wurde, die zwar nach dem, was Ovid explizit anführt, in erster Linie philosophisch-naturwissenschaftlichen Inhalts ist, jedoch ethische Fragestellungen nicht grundsätzlich ausschließen muss.

168 Nebenbei bemerkt kann dies dann noch mit dem Aspekt ergänzt werden, dass die Aussage auf die diegetische Kommunikationssituation bezogen und als metapoetischer Kommentar zu den „Metamorphosen“ selbst gelesen werden kann: Denn in diesem Gedicht, das gerade erzählt wird, ist der Vollzug dieses Sprechakts von genau diesem Sprecher in der Tat ein erst- und einmaliges Ereignis. 169 Vgl. auch den Hinweis bei Feeney 1999, 24, dass Ovid andernorts mittels primus sein eigenes bzw. eigenwilliges Ordnungs- und Zeitprinzip verdeutlicht, was er folgendermaßen zusammenfasst: „Ovid is, in sum, consistently evasive about offering connected rationales for the poem except those artistic ones for which he can claim full credit.“ Für primus als aitiologisches Signal s. Myers 1994, 65 (Anm. 17).

170 Eine Festlegung auf die eine oder die andere Zeitstufe beruht demnach allein auf den Signalen aus dem Kontext und der leserseitigen Bereitschaft, ihnen entweder zu folgen oder zu misstrauen. 
tonarent (70), quateret (71) und mearent (ebd.) - unterbrochen wird. Steht vorher alles in Abhängigkeit zum docebat (68) und macht den Inhalt von Pythagoras’ Vorträgen aus, ist das letzte Glied quodcumque latet (72) modal und temporal beinahe anakoluthisch davon abgesetzt. ${ }^{171}$

Damit lässt der Primärerzähler seinen Wissenshorizont gerade in dem Moment noch einmal durchscheinen, als er eigentlich dabei ist, das Wort abzugeben. Der Perspektivenwechsel allein ist unspektakulär bei einem Dichter, dessen Variationsstreben nur wenige Grenzen kennt. ${ }^{172}$ In Verbindung jedoch mit den Auffälligkeiten des nachfolgenden Satzes - die deutlich evozierte, aber problematische Parallele bei primus, der Synkretismus bei arguit und solvit sowie das trotz oder gerade durch die Metonymie sehr offenkundige In-Frage-Stellen der Erzählerautorität bei ora/ docta quidem ... sed non et credita ${ }^{173}$ - kann dies sehr wohl als Teil der Erzählstrategie ausgemacht werden. Und weil dieser Satz durch ein -que (72) direkt an das vorherige quodcumque latet (ebd.) anschließt, ohne dass wirklich klar ist, ob damit syntaktisch an den Haupt- oder Nebensatz oder nur allgemein an den Gedanken angeknüpft wird, ist es sehr naheliegend, die konkrete Kommunikationssituation als durch und durch unsicher zu beurteilen.

Der Status der Rede ist zweifelhaft zum einen in Bezug auf den zeitlich-örtlichen Rahmen, der nach historischen Maßstäben unmöglich ist und der sich zusätzlich durch diesen eigenwilligen Gebrauch polysemer und allusiver syntaktischer Strukturen seitens des Haupterzählers einer klaren Identifikation entzieht, zum anderen bezüglich ihres Sprechers Pythagoras, dessen Präsenz gleichfalls zeitlich unmöglich ist, auch ohne dass dessen Glaubwürdigkeit als Erzähler explizit noch hätte eingeschränkt werden müssen; und schließlich bleibt die Rede auch unklar hinsichtlich ihres Adressaten: Sich dessen Anwesenheit und unmögliche Begegnung mit Pythagoras vorzustellen, ermuntern die kontextuellen Implikationen geradezu demonstrativ, obwohl dieser nach seiner Frage zur Gründungsgeschichte Krotons in Vers 10 förmlich untertaucht, überdies in kein ausdrückliches Verhältnis zum Redner gebracht wird sowie in einer äußerst vagen Beziehung zu dessen Rede steht. Und letzterer Aspekt wird erst im Nachhinein klar.

171 Als allgemeine überzeitlich zu verstehende Aussage, wie sie ähnlich nur wenige Verse zuvor mit dem Imperfekt als vergangen beschrieben wurde (quae natura negabat/ visibus humanis - $63 \mathrm{f}$.), kann zwar auch quodcumque latet weiterhin auf die Diegese bezogen werden, der auffällige und direkte Kontrast zu den Passagen, die syntaktisch über die Konjunktivformen viel eindeutiger im Zusammenhang mit dem diegetischen Geschehen stehen, lässt dies aber eher unwahrscheinlich erscheinen.

Auch hier kann der zweifellos wichtige Metatext, s. dazu Hardie 2015, ad met. XV, 68-72, die unmittelbare Funktion im Text als sprachlich-syntaktische Auffälligkeit nicht erhellen. Erwähnenswert ist es aber, dass für den ovidischen Pythagoras selbst dieses quodcumque latet dann in der Vergangenheit liegt: quaeque diu latuere, canam (,was lange verborgen gewesen ist, will ich verkünden` - met. XV, 147).

172 Vgl. u.a. Kenney 2002, $88 \mathrm{f}$.

173 Zudem ein „[u]ngewöhnliches Enjambement“ (Bömer 1986, ad loc.). 
Das synchronistische Aufeinandertreffen von Numa und Pythagoras ist dabei ähnlich wie der Synchronismus bei den Panathenäen und Erichthonios keineswegs explizit zum Ausdruck gebracht, obwohl dieses hier sogar noch handlungsrelevanter ist als im anderen Beispiel. ${ }^{174}$ Darüber hinaus erwecken die Aussagen den Eindruck, als würden sie mitsamt ihren problematischen zeitlichen Implikationen nebeneinander bestehen können, da der Erzähler sie merkmallos äußert, d. h. ohne sie zusätzlich zu kommentieren und in ihrem Geltungsbereich einzuschränken. ${ }^{175}$

\subsubsection{Numa als Figur des Übergangs}

„Sollte das alles Zufall sein?“176 - in Anbetracht der schieren Fülle an Besonderheiten, die die Darstellung dieser Szenerie kennzeichnen, ohne überhaupt auf den Inhalt der intradiegetischen Erzählung selbst eingehen zu müssen, und darüber hinaus einen auffallend homogenen Effekt zeitigen, kann dies klar verneint werden. Für das Gesamtbild der hier betrachteten ersten Hälfte des 15. Buches wird klar, dass Ovid „nichts geringeres als seine eigene Version der römischen Geschichte“ schafft. ${ }^{177} \mathrm{Er}$ hebt diese deutlich als fiktional ab von der als faktual zu bezeichnenden und Faktizität beanspruchenden geschichtlichen Überlieferung. Wie die fiktiven Objekte Numa und Pythagoras in den „Metamorphosen“ weder fiktiv-real noch fiktiv-nicht-real sind, weil sie in der Form, wie sie vom Erzähler dargestellt werden, weder allein in der fiktiven noch allein in der realen Welt möglich sind, ohne nicht auch einen Aspekt der anderen Welt zu verkörpern, so ist auch Ovids „Numa-Geschichte“ als Ganzes weder nicht-real noch real, sondern als Hybrid beider Welten pseudo-real. ${ }^{178}$

Das Interessante daran ist nun, dass für diesen von der Erzählung veranlassten ontologischen Schwebezustand im zugrunde liegende Geschehen in der ersten Buchhälfte eine passgenaue thematische Entsprechung gegeben ist. Wie schon in früheren Abhandlungen beobachtet wurde, ist der Übergang von der griechischen zur römischen Welt nicht nur ein Grundthema in den „Metamorphosen“ schlechthin, sondern rückt insbesondere in den letzten beiden Büchern zunehmend in den Fokus. ${ }^{179}$ Eine entscheidende Stellung nehmen dabei sogenannte liminale Figuren ein, die wie z. B. im 14. Buch Kirke auf der Schwelle zwischen beiden Kulturen stehen und

174 Dort hätte Merkur Herse schließlich auch bei irgendeiner anderen Tätigkeit beobachten können.

175 Vgl. Hardie 2015, $486 \mathrm{f}$.

176 Bömer 1986, 253, zur auffälligen Zurückdrängung Numas in den „Metamorphosen“ im Kontrast zu den „Fasten“ (fast. III, 153f.) und der kurzen Erwähnung als exemplum in den Exilbriefen (Pont. III, 3, 44).

177 Schmitzer 2006, 37. Vgl. auch Santini 1998, 53f. und Galinsky 1998, 334.

178 S. o. Kap. 3.2.4.

179 Vgl. Barchiesi ${ }^{4} 2013$, CXXIV-CXXIX. 
deswegen über die symbolische Bedeutung hinaus allein mit ihrer physischen Existenz eine gegenseitige interkulturelle Vermittlung verdeutlichen. ${ }^{180}$

$\mathrm{Zu}$ Beginn des 15. Buches schlägt sich dieser Aspekt an der Person Numas auf zweierlei Weise nieder: Zum einen befindet dieser sich hinsichtlich seiner persönlichen Umstände in einem liminalen Zustand zwischen seinem früheren, nicht näher explizierten Dasein und seinem vom Gerücht wahrheitskündend vorweggenommenen Sein als römischer König (destinat ... praenuntia veri/ fama - 3f.). Er steht also zum Zeitpunkt der diegetischen Handlung genau zwischen dem einen und dem anderen: Nicht ist er nur mehr bloß ein berühmter Mann (clarum - 3), aber auch noch nicht derjenige, der das imperium (ebd.) bereits in Händen hält. ${ }^{181}$ Diese Interimsphase ist erst durch den Erzählerkommentar nach Beendigung von Pythagoras’ Rede (479-481) endgültig aufgehoben: Dann nämlich, so der Erzähler, soll er die Leitung über das Latinervolk angenommen haben (accepisse Numam populi Latialis habenas - 481). ${ }^{182}$ Alles aber, was in den über 400 Versen dazwischen erzählt wird und hinsichtlich dessen zu einem überwiegenden Teil nur impliziert wird, dass Numa als Zuhörer zugegen ist, findet in diesem schwebeähnlichen Transit vom Alten zum Neuen in Kroton statt. ${ }^{183}$

Dieser situativen Liminalität auf der einen Seite steht auf der anderen Seite das noch entscheidendere sozusagen persönlich-charakterliche Schwellen-Dasein gegenüber. ${ }^{184}$ Denn auch in dieser Hinsicht wird Numa als jemand beschrieben, der offenbar noch nicht dort ist, wo er sein möchte: Er verfügt noch nicht über ausreichend Wissen der lokalen Traditionen (non ... satis cognosse - 4), ${ }^{185}$ er denkt an Größeres (maiora ... concipit - 5f.), ist ein Fragender/Suchender (requirit und quaerenti - 6 bzw. 10) und wird aus leidenschaftlichem Interesse (huius amor curae - 7) (186 $^{186}$ zum forschenden Wanderer, im Zuge dessen er auch sein altes Dasein in seiner Heimat zurücklässt (patria Curibusque relictis - ebd.) und in das pseudo-reale Kroton gelangt. Wenn er dort dann auf eine nicht näher spezifizierte Art mit Pythagoras als dem Liebhaber der Weisheit schlechthin, dem kommt, dann hat Numa vorher schon durch seinen amor (7) oder besser noch seinen

180 Vgl. Myers 2009, 6-8.

181 Das wird ihm bis dato - mehr oder minder verbindlich - ja nur von fama zuerkannt.

182 Der Umstand, dass der Vorgang syntaktisch abhängig ist von der mit ferunt ausgedrückten Distanzierung des Erzählers, schwächt weniger den Fakt an sich ab als die Art und Weise, wie dieser genau zustande kam. Denn die im Anschluss stehenden Verben - docuit (483), traduxit (484) und peregit (485) - stehen alle im Perfekt und weisen Numa als in der Diegese historisch handelnden König (via Metonymie bei regnum - 485) aus.

183 S. zum Reisemotiv von Albrecht 2014, $99 \mathrm{f}$.

184 Wegweisend dafür die Anmerkung von Hardie 2015, ad met. XV, 4-11: „Numa piuttosto prova

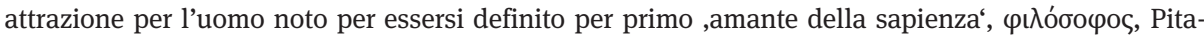
gora."

185 Dass dies in eklatantem Widerspruch zu dessen eigentlicher Abstammung steht, scheint Ovid für die beabsichtigte Charakterisierung der Figur in Kauf genommen zu haben. S. o. S. 200, Anm. 145. 186 Zu cura s. Bömer 1986, ad loc. 
$\varepsilon^{\prime} \rho \omega \varsigma^{187}$ unter Beweis gestellt, dass er eigentlich selbst ein Philosoph par excellence ist. ${ }^{188}$ Denn sein Streben bzw. Verlangen nach Einsicht kommt der platonischen Definition des $\varepsilon^{\prime} \rho \omega \varsigma^{189}$ als Begehren des noch nicht Vorhandenen sehr nahe und er selbst gleicht dessen Beschreibung der Philosophierenden: Diese sind bekanntlich weder weise noch unverständig, sondern befinden sich in einer Mittelstellung zwi-

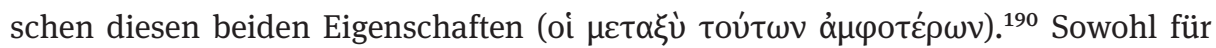
den amor - in Platons Allegorie ein Kind der Armut (Пعvía) und des Ausweges (Пópos) - ${ }^{191}$ ist es kennzeichnend, dass er ein Defizit zusammen mit dem Streben aufweist, diesem Defizit zu begegnen, als auch für den ihn verkörpernden Philosophen, der aus Einsicht in das eigene Nichtwissen nach Wissen strebt.

Der Numa zu Beginn des 15. „Metamorphosen“-Buches ist daher auf geradezu prototypische Weise als Philosoph charakterisiert: Er ist sich seines Unwissens bewusst und strebt nach neuen oder weiteren Kenntnissen - eine wortwörtlich wissenschaftliche Tätigkeit, die ihn zu seiner Wanderschaft veranlasst. Nichts Anderes ist

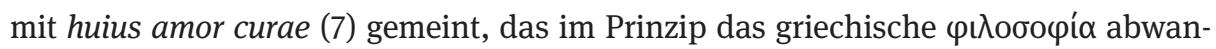
delnd übersetzt und dessen Pronomen huius sich ausdrücklich auf den Mangel als in diesem Sinn erotischen Wesenszug bezieht, der in den Versen 4-6 expressis verbis zum Ausdruck kommt. Pythagoras, so gesehen das Ziel von Numas philosophischem Streben, müsste dann logischerweise in den „Metamorphosen“ die Aufgabe haben, einem Suchenden und nach Wissen Strebenden Antworten zu geben. ${ }^{192}$

Und diesem Aspekt trägt Ovid tatsächlich sehr detailliert Rechnung: Der vir ortu

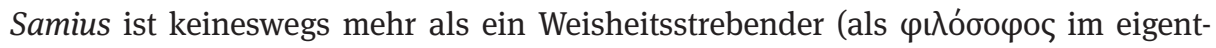
lichen Sinn) charakterisiert, sondern als einer, der die Weisheit bereits erlangt hat, d. h. der ein Weiser (бофóৎ) ist. ${ }^{193}$ Ausdrücklich ist dies festgehalten in der Verallgemeinerung perspexerat omnia (65), womit seine Weisheit sowohl als Zustand

187 S. dazu besonders die Diotima-Rede im „Symposion“ (Plat. symp. 201d-212c).

188 Eine Diskussion zur Frage, ob Numa vor dem Hintergrund der Plutarch-Vita und Platons „Politeia“ ein Philosophenkönig sei, findet sich bei Boulet 2005.

Dass sich ein Buch „die Kritik an Platons Liebesphilosophie“ in den „Metamorphosen“ auf den Einband oder die „Formen des Eros“ in den Titel schreibt (gemeint ist Hösle 2020), ohne allein diesen amor (met. XV, 7) auch nur zu beachten, von einer Kritik ganz zu schweigen, ist unerklärlich, aber vielsagend.

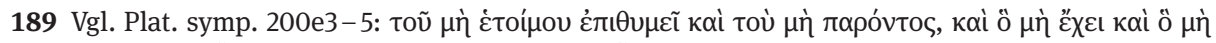

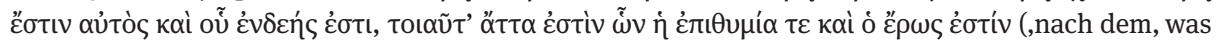
nicht bereitliegt, verlangt er, und nach dem nicht Vorhandenen, und was er nicht hat und was er nicht selbst ist und woran er bedürftig ist, derlei sind die Dinge, nach denen es das Verlangen sowie die Liebe gibt‘).

190 Vgl. ebd. 204a7-b2.

191 Vgl. ebd. 203b-e.

192 Eine Rolle als Philosoph ist damit unpassend, da diesen ja nach der platonischen Definition ein Wissensdefizit und ein Mangelzustand auszeichnet.

193 Dies zeigen schon die beiden einzigen neben fuit (60) im Perfekt stehenden Verben adiit (63) und hausit (64), deren Handlung als abgeschossen gekennzeichnet ist: Pythagoras hat sich den Göttern geistig genähert und hat die Geheimnisse der Natur mit seinem inneren Auge ausgeschöpft. 
sprachlich fixiert als auch kausal mit seiner Lehrtätigkeit verknüpft ist, die in den nächsten Versen (66-72) anhand der bereits erwähnten Imperfekt-Verben als eine andauernde Tätigkeit vorgestellt wird. In der diegetischen Gegenwart hat der ovidische Pythagoras also das Dasein des Philosophen hinter sich gelassen. Denn derjenige, so wiederum Platon, der weise ist, muss logischerweise nicht mehr danach streben, es zu werden - d. h. wortwörtlich Philosophie betreiben und ein Philosoph sein: Er besitzt die Weisheit schon und befindet sich in einem gottgleichen Zustand. ${ }^{194}$

Ausgehend wiederum von dieser Analogie von Weisheit und Göttlichkeit erhellt sich auch die Beschreibung dessen, wie Pythagoras zu seinem Wissen gelangt ist: indem er sich in den Bereich des Göttlichen vorgewagt hat, das dem menschlichen Schauen natürlicherweise versagt ist (62-65). Weil ihm das aber kraft seines Verstandes (mente und oculis ... pectoris - 63f.) gelang, bleibt er als Figur menschlich und sein Weg zu diesem Wissen realistisch, wohingegen ihm seine Weisheit, basierend auf göttlichem Wissen sowie Wissen vom Göttlichen, mit dem Übermenschlichen in Verbindung bringt. ${ }^{195}$

Pythagoras steht somit ebenso auf einer Schwelle zwischen den Welten. Er ist physisch ein Mensch wie jeder andere, aber innerlich über das Menschliche erhaben und kann durch sein Wirken als Lehrer, das am manifestesten dann in Form seiner Rede - deren unmittelbarer Zweck schließlich ein didaktischer ist - ${ }^{196}$ in Erscheinung tritt, zwischen dem Göttlichen - symbolisiert in der Weisheit - und dem MenschlichStrebenden - idealerweise personifiziert durch Numa - vermitteln. Er ist dadurch der ideale Gesprächspartner für den philosophierend Umherwandernden. ${ }^{197}$

Nach Beendigung der Pythagoras-Rede in den „Metamorphosen“ und der mit ihr auch performativ erfolgten Belehrung ist der fiktive Numa somit jemand, der gefunden hat, wonach er gesucht hat. Immerhin soll er, so der Erzähler, instructus (479) gewesen sein, als er zurückgekehrt ist und die Herrschaft angetreten hat. Die liminale Phase Numas sowohl in Bezug auf sein Noch-Nicht-Sein als König als auch auf sein noch defizitäres und zum Philosophieren anregendes Wissen ist zu diesem Zeitpunkt be-

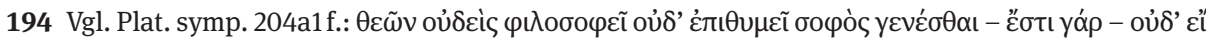

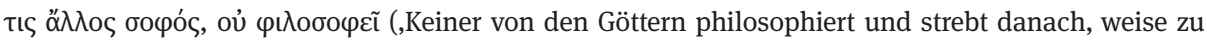
werden - er ist es nämlich - und auch kein sonst irgendwie Weiser betreibt Philosophie.`).

195 Dass die kulthafte Verehrung des Pythagoras in der Antike für eine solche Charakterisierung den passenden Anknüpfungspunkt geboten hat, ist sehr wahrscheinlich. S. dazu Bömer 1986, ad met. XV, 60 - 62. Das Motiv des inneren Auges findet sich u. a. auch im „Symposion“ (Plat. symp. 219a2f.) sowie bei Cicero (nat. I, 19) und unterstreicht die philosophische Motivik an dieser Stelle. Vgl. Hardie 2015, ad met. XV, $63 \mathrm{f}$.

196 Vgl. die Zusammenfassung bei Bömer 1986, $269 \mathrm{f}$.

197 Numa dürfte sich daher eher weniger für den $\varphi \iota \lambda$ óøo

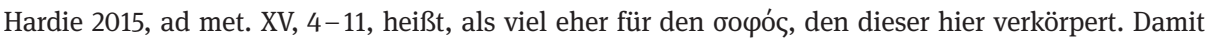
vertauscht Ovid in gewisser Weise die Rollen, die die beiden Personen üblicherweise haben: Numa, der $\theta \varepsilon \tilde{o}$ å ảvń $\rho$, ist zunächst Philosoph, während Pythagoras, der Philosoph, eine sozusagen transphilosophische gottgleiche Figur ist. 
endet und er kann selbst als die Mittlerfigur zwischen Gott und Mensch in Erscheinung treten. Dazu hat die Tradition ihn, den $\theta \varepsilon \tilde{o}$ ○ åvń $\rho$, schließlich gemacht.

Ovid gibt deswegen durch seine Geschichte auf seine ganz eigene Weise eine Aitiologie für Numas Kenntnisse und sozusagen für seine Lehrbefähigung, was passenderweise dann auch genau mit diesem Aspekt der Vermittlung zwischen göttlicher Weisheit und menschlicher Diesseitigkeit abgeschlossen wird:

sacrificos docuit ritus gentemque feroci

adsuetam bello pacis traduxit ad artes. ${ }^{198}$

Bei Numa, in dieser Form als ein weiser Mann inszeniert, offenbart sich deshalb noch eine letzte wichtige Parallele einerseits zu Pythagoras, dessen Tätigkeit (docebat - 68) er nun selbst ausführt (docuit - 483), und andererseits zum platonisch-philosophischen Eros. Denn durch dieses halb göttlich, halb menschliche Dasein ist er wie Eros in einem „daimonischen“ Zustand, dessen Aufgabe darin besteht,

,den Göttern das von Menschen Stammende und den Menschen das von Göttern Stammende übersetzend zu beschaffen, von den Einen die Bitten und Opferhandlungen, von den Anderen ihre Gebote und Erwiderungen für die Opferhandlungen. ${ }^{199}$

Eben dazu leistet er als König und $\delta \alpha \mu$ óvıoৎ $\alpha$ vn $\rho^{200}$ in Form seiner Unterweisungen keinen geringen Beitrag und in dieser Weise hat es zuvor auch Pythagoras bei diesem selbst im Zuge der fiktiven und für den Leser sozusagen „live“ verfolgbaren Instruktion bewerkstelligt. $^{201}$

Dass ein solcher Vorgang sehr wenig überzeugend wäre, wenn er aus einer historischen Perspektive erzählt bzw. nacherzählt worden wäre, dürfte deshalb nicht allein aus dem leicht zu erbringenden Beweis seiner zeitlichen Unmöglichkeit ersichtlich werden; noch viel augenfälliger ist es doch, dass die Anschaulichkeit und Plausibilität der ovidischen Erzählung sich auf ein vielfältiges, explizit wie implizit erfolgendes und strukturell wie thematisch motiviertes Beziehungsgeflecht stützt, aber letzten Endes nicht auf die außertextliche Faktizität ihrer Objekte. ${ }^{202}$ Dürfte doch

198 Met. XV, 483f.: ,Er lehrte die opferbezogenen Gebräuche und führte ein Volk, gewöhnt an wilden Krieg, an die friedlichen Künste heran. ' Weiteres zu dieser Stelle bei Hardie 2015, 547-549. S. auch o. Kap. 5.1.2.5c.

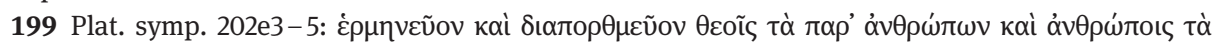

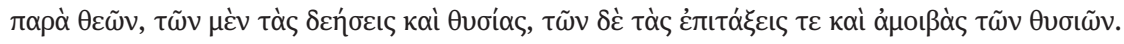

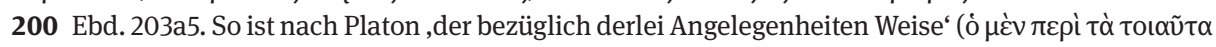

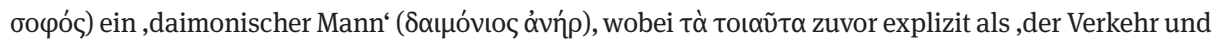

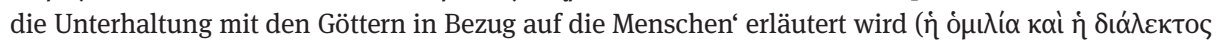

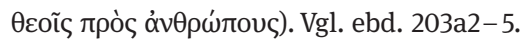

201 Von anfänglichen „philosophischen Neigungen“, die „nach dem Pythagoras-Abschnitt“ nicht mehr vorhanden sind, spricht auch Granobs 1997, 115.

202 Vgl. Vial 2010, 75f. Dies sollte bei aller historisch-politischer Interpretationsarbeit, so wichtig sie fraglos auch an dieser Stelle ist, nicht übersehen oder als nebensächlich abgetan werden. 
gerade bei einem Mythos, der nach rationalen und historischen Begriffen tot ist, ${ }^{203}$ das Ausschöpfen der in der dichterischen Fiktionalität liegenden Ausgestaltungsmöglichkeiten ganz an seinem Platz sein, um ihn auf umso anschaulichere und überzeugendere Weise wiederzubeleben. ${ }^{204}$

\subsection{Zusammenfassung}

Die Funktion der poetischen Synchronismen könnte daher im Allgemeinen damit beschrieben werden, dass Geschichte an der Geschichte vorbeierzählt wird. Die eine Geschichte ist die, die als diegetisches Geschehen stattfindet, und die andere eine als vergangen betrachtete, historisch-philologisch rekonstruierbare extradiegetische Realität, die auf der Faktizität bzw. der Historizität der zugrunde liegenden Zusammenhänge basiert und die zudem dem Wissensstand des Primärerzählers und des idealerweise vorauszusetzenden Rezipienten entspricht. ${ }^{205}$

Kennzeichnend für Ovid ist, dass er dabei eine der grundlegenden Konventionen epischen Erzählens hintergeht, ${ }^{206}$ indem er in formaler Hinsicht scheinbar getreu dieser Konvention schildert und diesen Eindruck sogar auf vielfältige Weise zu bestärken weiß, jedoch inhaltlich sehr offensichtlich davon abweicht, weil er seinen eigenen Erfahrungshorizont in der erzählten Welt mitrepräsentiert, ohne dies explizit zu markieren. ${ }^{207}$ Die in diesen Erzähleraussagen liegenden zeitlichen Implikationen sei es wie im Falle der Epitheta ornantia die der Gleichzeitigkeit zwischen Attribut und Nomen oder die jeweils durch die Aktualisierung zum Ausdruck gebrachte Zeitbeziehung - stehen deshalb unterschiedslos neben all den Informationen, die in der diegetischen Umgebung für das in ihr erfolgende Geschehen relevant sind. Während dies in den meisten Fällen keine weiteren Konsequenzen hat, wird dies dann aber

203 So die Überschrift von Humm 2004. Vom Mythos allgemein, der „religiös tot“ ist, spricht auch von Albrecht 1981, 2342.

204 Passend hierzu nochmals von Albrechts Vergleich von Ovid mit Odysseus, der den Schatten der Unterwelt frisches Blut zuführt und sie so für die Interaktion mit Menschen befähigt. Vgl. ebd., 2337. 205 Als drei weitere, eher geringfügige poetische Synchronismen neben der Pygmalion-Geschichte (s. o. Kap. 5.1.2.2) können zudem noch angeführt werden: erstens met. IV, 802f.: Perseus redet mit nunc quoque von einem Status Quo, der sich erst nach einer späteren Handlung, die Ovid in met. V, 242-249 erzählt, aber ohne auf jenes Spezifikum (das Gorgoneion) zu Sprechen zu kommen, ergibt (vgl. Bömer 22011, 227 und Barchiesi/Rosati 2007, ad met. IV, 802f.). Zweitens met. IX, 686-694, weil der Isis-Kult keine historische Tatsache im Kreta „dieser“ Zeit war - das kann aber schlicht auch als Aktualisierung gewertet werden (vgl. Bömer 1977, 470 und Kenney 2011, ad met. IX, 686-694). Drittens met. XIV, 564 f., weil die aus Aeneas' Schiffen entstandenen Delphine zum Zeitpunkt der Handlung noch nicht das versteinerte Phäaken-Schiff gesehen haben können (vgl. Bömer 1986, ad met. XIV, 563-565).

In den ersten beiden Fällen handelt es sich daher, anders als im Register von Hardie 2015, 660, angegeben, nicht um Anachronismen (auch Bömer spricht von „Anachronismen“), sondern um Synchronismen.

206 S. dazu Surkamp 2002, 158-161.

207 Vgl. Barchiesi 2002, $196 \mathrm{f}$. 
bedeutsam, wenn eine Art geschichtlicher Prozess in der fiktiven diegetischen Welt erzählt wird. Dann nämlich steht diese Mythengeschichte im Widerspruch zum unmittelbaren Kontext - entweder durch die Informationen aus dem Kontext selbst oder aus einer gegebenenfalls vorhandenen außertextlichen historisch-literarischen Tradition.

Das vorgebliche Bild einer eindimensionalen Erzählung, in der der epistemische Unterschied von Erzähler und Erzähltem als geringfügig vernachlässigt und der Erzählinstanz dabei ein gewisser Vertrauensvorschuss entgegengebracht wird, als ob diese auch mit einer derartigen Privilegierung verantwortungsvoll umzugehen wisse, steht so entschieden zur Disposition und fordert zu einer vorsichtigeren bzw. komplexeren Auseinandersetzung mit den vorgebrachten Aussagen heraus. ${ }^{208}$

Dabei ist noch einmal $\mathrm{zu}$ betonen, dass die bei oberflächlicher Betrachtung deutlich scheinenden Widersprüche weder mit assertiver Stärke vom Erzähler mitgeteilt sind noch auf das diegetische Geschehen bezogen werden können. Immer basierend auf einer Aktualisierung oder einem Anachronismus - ob nun z. B. das Attribut nobilis aere bei Corinthus (met. VI, 416), der Panathenäen-Zug (met. II, 711713) oder die Lehrtätigkeit des Pythagoras (met. XV, 60 - 478) - entstammen sie einer extradiegetischen Perspektive. Der Synchronismus beruht deshalb auf der mitunter folgenreichen Annahme, den zeitlichen Zustand, wie er von dieser Aussage impliziert wird, direkt mit den anderen Objekten in Beziehung setzen zu können: z. B. das erzberühmte Korinth mit dem Theben zur Zeit des Pelops.

Dieser Graubereich wird bei den Panathenäen- und Numa-Pythagoras-Synchronismen auch dadurch aufrechterhalten, dass jeweils eines der fiktiven Objekte in die Peripherie des Geschehens gerückt - so bei Erichthonios und Numa - und das andere nur über die Summe seiner Eigenschaften präsentiert wird - bei den Panathenäen und Pythagoras -, sodass sie zwar wahrnehmbar sind, aber durch ihre marginale Präsenz keinen übermäßigen Anlass bieten, die eigentliche Handlung mit ihrem Widerspruch zu überschatten.

Auf diese Weise kann über das durch Aktualisierungen sehr eingängige diegetische Geschehen hinaus - Städte entsenden Trauergesandtschaften, in Athen findet ein Festzug statt, bei dem sich adlige Mädchen in ihrer ganzen Pracht präsentieren, und in Kroton hält ein weiser Mann einen Lehrvortrag - als sekundärer Aspekt die Erzählung selbst und ihr Gemacht-Sein in den Fokus rücken. Die poetischen Synchronismen bestärken dies, indem durch sie die Fiktionalität der Erzähleraussagen, d. h. ihr Ausnutzen der poetischen Lizenz zum Entwerfen einer eigenen, pseudorealen Welt, sichtbar wird.

208 Vgl. ebd., 185. 